\title{
Evaluation of Barriers to Referral for Cancer Predisposition Syndromes in Pediatric Oncology Patients
}

\author{
by \\ Rosemarie E. Venier \\ BSc, McMaster University, 2010 \\ MSc, McMaster University, 2012
}

\author{
Submitted to the Graduate Faculty of the \\ Graduate School of Public Health in partial fulfillment \\ of the requirements for the degree of \\ Master of Science
}

University of Pittsburgh 


\section{UNIVERSITY OF PITTSBURGH}

\section{GRADUATE SCHOOL OF PUBLIC HEALTH}

This thesis was presented

by

\section{Rosemarie E. Venier}

It was defended on

April 13, 2020

and approved by

Robin Grubs, MS, PhD, LCGC, Associate Professor of Human Genetics, Licensed Genetic Counselor, Director Genetic Counseling Program, Department of Human Genetics, University of Pittsburgh

Kelly M. Bailey, MD, PhD, Assistant Professor, Department of Pediatrics, Division of Pediatric Hematology/Oncology, University of Pittsburgh School of Medicine

Elena Kessler, MS, LCGC, Senior Genetic Counselor, Department of Pediatrics, Division of Medical Genetics, University of Pittsburgh

Thesis Advisor: Julia Meade, MD, Assistant Professor, Department of Pediatrics, Division of Pediatric Hematology/Oncology, University of Pittsburgh School of Medicine 
Copyright (C) by Rosemarie E. Venier 


\title{
Evaluation of Barriers to Referral for Cancer Predisposition Syndromes in Pediatric Oncology Patients
}

\author{
Rosemarie E. Venier, MS \\ University of Pittsburgh, 2020
}

\begin{abstract}
Genomic medicine and the use of genetic information in pediatric oncology has provided insight on the molecular underpinnings of childhood cancers and has demonstrated that cancer predisposition syndromes (CPS) are underdiagnosed. Diagnosis of a CPS has important implications for the patient and their family. In childhood, CPS are often diagnosed by geneticists or oncologists with expertise in CPS following a malignancy, however, this requires a member of the care team, most commonly, the treating oncologist to suspect a CPS and refer them for assessment. We sought to understand current referral practices of pediatric oncology healthcare providers and barriers to referral for evaluation of a CPS. An online survey was sent to members of the Children's Oncology Group. Of the 189 respondents, $80.4 \%$ were pediatric hematologists/oncologists and most (69\%) used formal guidelines to aid in referral assessment. Guideline use was associated with a higher proportion (>5\%) of patients with a CPS in the respondent's practice. Participants were more likely to refer patients with malignancy and additional features of a CPS than for a specific type of cancer, despite the use of guidelines. Most respondents indicated they would rarely refer patients with tumors highly associated with CPS. Patient/parent knowledge of family history was considered the most challenging barrier to obtaining a family history, though a thorough three-generation pedigree was not consistently attempted. Overall, participants indicated the most significant barrier to referral was priority given the patient's more immediate care needs. Other barriers to genetics referral identified elsewhere
\end{abstract}


by primary care physicians were unlikely to be considered barriers in this population. These data suggest that pediatric hematologists/oncologists experience different barriers than other specialties and may benefit from further education about CPS, and clearer referral guidelines. Furthermore, utilization of a genetic counselor within the pediatric oncology clinic may encourage CPS assessment but allow oncologists to focus on the patient's immediate care needs. These findings may facilitate increased referrals for CPS evaluation which improve public health by identifying patients and families who may benefit from preventative care measures. 


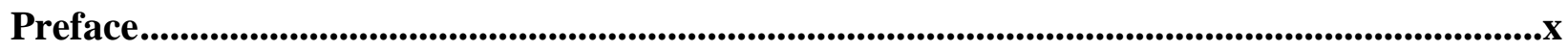

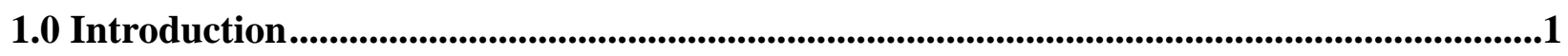

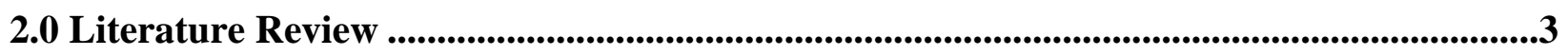

2.1 Pediatric Cancer ....................................................................................................................................3

2.2 Cancer Predisposition Syndromes ...................................................................................................4

2.2.1 Prevalence of Cancer Predisposition Syndromes.........................................................5

2.3 Barriers to Genetics Referrals.......................................................................................9

2.3.1 Barrier: Provider Knowledge .................................................................................................9

2.3.1.1 Genetics Knowledge...............................................................................................9

2.3.1.2 Family History Information.........................................................................12

2.3.2 Barrier: Evidence ......................................................................................................................15

2.3.2.1 Perceived Clinical Utility .....................................................................................15

2.3.2.2 Tools ..................................................................................................................16

2.3.3 Barrier: System ..........................................................................................................................19

2.3.3.1 Accessibility ........................................................................................................19

2.3.3.2 Cost...................................................................................................................21

2.4 Summary …..........................................................................................................................................22

3.0 Manuscript..............................................................................................................................23

3.1 Background ..............................................................................................................................................23

3.2 Methods …..............................................................................................................................................25

3.2.1 Recruitment ...........................................................................................................................25 
3.2.2 Survey Design ......................................................................................................................25

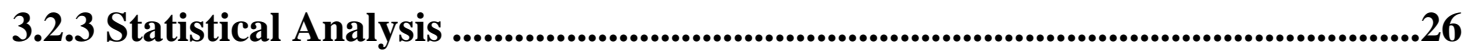

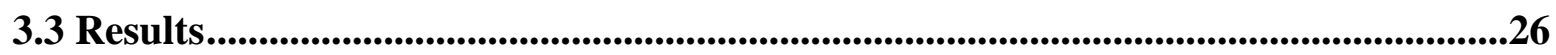

3.3.1 Demographics .........................................................................................................................26

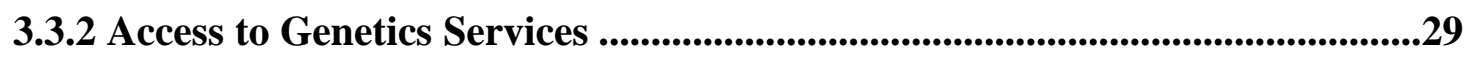

3.3.3 Referral Practices.................................................................................................................30

3.3.4 Family History Elicitation .................................................................................................36

3.3.5 Barriers to Complete Family History .......................................................................37

3.3.6 Barriers to Genetics Referrals ...................................................................................38

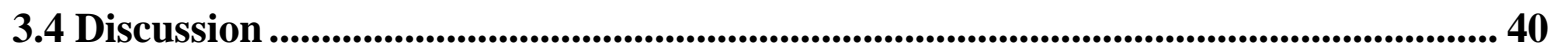

3.4.1 Current Practices and Perceived Barriers to Referral ........................................40

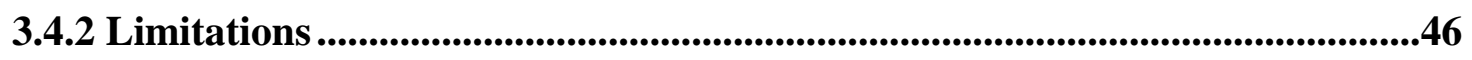

3.4.3 Future Directions ...............................................................................................................46

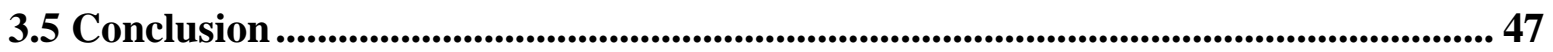

4.0 Genetic Counseling and Public Health Significance...................................................................... 49

Appendix A Supplemental Figures.......................................................................................................... 51

Appendix B IRB Approval Letter ....................................................................................................... 54

Appendix C Recruitment Email ............................................................................................5 55

Appendix D Survey ….................................................................................................................................... 57

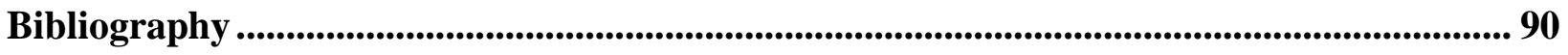




\section{List of Tables}

Table 1. Demographic characteristics of survey respondents. ............................................ 28

Table 2. Access to genetics services. ........................................................................................ 30

Table 3. Referral practices.................................................................................................... 32

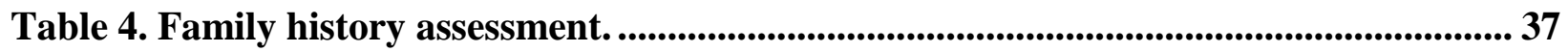

Appendix Table 1. Family history importance............................................................................... 51

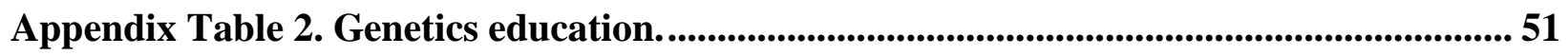

Appendix Table 3. Genetic testing......................................................................................................... 52

Appendix Table 4. Family history elicitation of new pediatric oncology referral. ................ 53

Appendix Table 5. Family history elicitation of new pediatric oncology referral with a

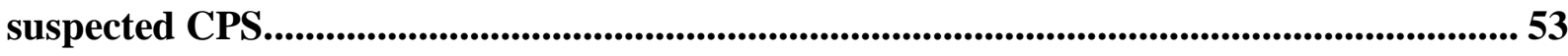




\section{List of Figures}

Figure 1. Likelihood to refer for CPS evaluation.......................................................... 35

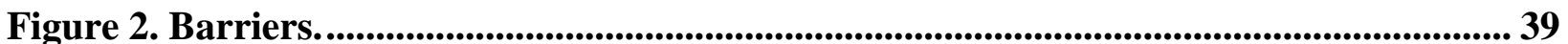




\section{Preface}

Thank you to my committee members Dr. Julia Meade, Dr. Kelly Bailey, Elena Kessler

and Dr. Robin Grubs for their mentorship on this project. Your guidance was invaluable and without it this work would not have been possible.

Thank you also to the family and friends who have supported me throughout the research process and who encouraged me to pursue this degree. 


\subsection{Introduction}

Pathogenic germline mutations in cancer predisposition genes confer an increased lifetime risk for cancer and are classified as cancer predisposition syndromes (CPS). Historical observational data predicted $10 \%$ of all pediatric cancers were due to a CPS, however, in the era of genomic sequencing, data now suggest 7.6-35.5\% of childhood cancers are due to an underlying CPS. ${ }^{1-10}$ While prevalence varies due to a number of factors, these data suggest that overall, CPS are underdiagnosed in the pediatric population.

Early diagnosis of individuals with a CPS improves patient outcomes by informing management and surveillance, and may have familial implications. ${ }^{10-13}$ Referral guidelines have been established to aid practitioners in the identification of patients who would benefit from further assessment by a genetics professional. ${ }^{14-17}$ It is currently unknown how often children with a suspected CPS are referred for further evaluation but rates of genetic referral uptake for adult oncology range from $22-68 \% .{ }^{18-22}$ If rates are similar for the pediatric population, there may be a significant number of CPS cases undiagnosed due to low referral uptake, however, if referral does not occur, uptake is irrelevant. Numerous barriers to genetics referrals have been identified in other specialties but data in the pediatric oncology setting are sparse. ${ }^{19,23-32}$

The specific aims of this study were to:

i. Understand referral practices of pediatric oncology healthcare providers (HCP) for patients with a suspected CPS

ii. Define recommendations to improve genetics referrals for patients with a suspected CPS by pediatric oncology HCP 
The Children's Oncology Group (COG) is a pediatric cancer research group supported by the National Cancer Institute. It was chosen as the study population because its members make up a large proportion of pediatric oncology HCP in America. Survey design was modelled after published studies in other medical disciplines, with additional questions formulated to address issues specific to pediatric oncology. The goals of this project were to elucidate current referral practices of pediatric oncology HCP, to identify perceived barriers to referral for patients with a suspected CPS, and to formulate recommendations to improve referral behaviors of pediatric oncology HCP for patients with a suspected CPS. 


\subsection{Literature Review}

\subsection{Pediatric Cancer}

Cancer is the most common cause of death by disease in children aged 1-14 in the United States. In 2019, an estimated 11,060 children will be diagnosed with cancer and nearly $11 \%$ will die from their disease. Survival rates vary by tumor type and age at diagnosis; the overall survival for a child diagnosed with neurofibromatosis type 1 and optic glioma is $100 \%$ compared to $40 \%$ for a child with low hypodiploid acute lymphoblastic leukemia, a leukemia commonly associated with Li Fraumeni syndrome (LFS). ${ }^{33-35}$

Identification of individuals with a cancer predisposition syndrome may reduce pediatric cancer mortality by utilizing prevention and early detection measures. Current research aims to identify novel treatments that will decrease the mortality rate in the pediatric cancer population, as standard agents are often ineffective in advanced disease. More specifically, 30-40\% of standard of care chemotherapeutics are ineffective in metastatic, refractory, or relapsed pediatric solid tumors. ${ }^{6}$ In addition to more effective therapeutics, screening and/or risk reducing surgery may be beneficial when a predisposing germline mutation has been identified in a child. In fact, preventative measures have been found to improve outcomes for individuals with cancer predisposition syndromes such as LFS and multiple endocrine neoplasia type II. ${ }^{13,36}$ 


\subsection{Cancer Predisposition Syndromes}

Cancer predisposition syndromes (CPS) are caused by pathogenic germline mutations in tumor suppressor genes, or more rarely oncogenes, which confer an increased risk for cancer. A number of professional societies recognize the importance of early detection of cancer in individuals with a CPS. ${ }^{14,15,17,37}$ Early detection may benefit the patient and his or her family in a number of ways including disease management options, screening and prevention for the patient and family members, and providing an answer for why a child has cancer. ${ }^{11}$

LFS provides an example of the benefit of identifying individuals with a CPS and implementing cancer surveillance. LFS is caused by germline loss of function mutations in TP53, resulting in multiple primary tumors and/or tumors at a young age (often before age 30). ${ }^{38-40}$ Characteristic LFS cancers include tumors of the breast, brain, adrenal cortex, and bone and soft tissue sarcomas. Early identification of LFS allows for comprehensive screening beginning at birth, avoidance of radiation therapy which is associated with increased secondary tumor risk, and testing/screening of family members. ${ }^{41}$ Clinical surveillance of individuals with LFS increases 5year overall survival from $59.6 \%$ to $88.8 \% .^{13}$

To begin surveillance at birth, there must already be a suspicion or diagnosis of a CPS in the family, which stresses the importance of obtaining a thorough and complete family history in the oncology and primary care setting. An Australian study of 648 childhood cancer survivors, illustrated the importance of revisiting family history information. Of the survivors, $2 \%(16 / 648)$ reported they had been diagnosed with a CPS since their cancer diagnosis, however, following analysis of their family history, $11 \%$ (69/648) met Chompret criteria for clinical diagnosis of LFS. The median time between cancer diagnosis and family history update for the study was 16 years (range: 5-43 years). ${ }^{42}$ Unfortunately, for those individuals with a de novo mutation or a CPS with 
lower penetrance, they may be the first in the family to be identified following a cancer diagnosis. Other indications a child should be assessed for a CPS include specific physical features, high risk tumor types, and incidental findings from germline or somatic testing. ${ }^{15}$

While some CPS are associated with additional characteristics, there are several reasons why individuals with physical features of a CPS may not be diagnosed. ${ }^{17}$ The time surrounding a pediatric cancer diagnosis is usually stressful and clinical efforts are often focused on treatment options. Furthermore, due to variable expressivity, not all individuals with a CPS have suggestive physical features, and there is also evidence that pediatricians and oncologists whose training does not focus on genetic syndromes, may not recognize the physical signs of such rare disorders. ${ }^{1,11,43}$

Merks and colleagues argue all children diagnosed with cancer should be evaluated by a clinical geneticist or other provider skilled in dysmorphology. Following physical examination of 1,073 children with cancer, they diagnosed $3.9 \%$ (42/1073) with a CPS and identified 3.3\% (35/1073) with a suspected CPS. ${ }^{43}$ Their research suggests genetics specialists with dysmorphology expertise are the appropriate HCP to diagnose these individuals. A study of 370 childhood cancer survivors found 29\% (109/370) were eligible for genetics follow up based on personal/family medical history and published literature as assessed by a genetic counselor, indicating a proportion of individuals with a CPS may be missed by standard referral routes and genetics specialists should be involved in CPS assessment. ${ }^{44}$

\subsubsection{Prevalence of Cancer Predisposition Syndromes}

Previously, cancer registries and family studies predicted about $10 \%$ of all pediatric cancers were due to an underlying CPS. ${ }^{1,10}$ Further research has focused on identifying genetic drivers of tumorigenesis with the use of next generation sequencing (NGS)., ${ }^{2,3-9}$ These studies aim to 
identify novel drug targets, guide tumor surveillance protocols, identify patients that may benefit from genetic counseling and/or a genetics assessment, and provide empirical prevalence data.

Collectively, sequencing data suggest between $7.6-35.5 \%$ of pediatric cancers are due to pathogenic germline mutations. When comparing studies, germline mutation frequency varies by tumor type, study population, and the authors' definition of a 'reportable pathogenic germline mutation". The two largest pediatric cancer sequencing studies report 7.6\% ( $\mathrm{N}=914)$ and 8.5\% $(\mathrm{N}=1,120)$ of patients possess a pathogenic or likely pathogenic germline mutation in a cancer predisposition gene. ${ }^{2,3}$ The studies differ in the number of cancer predisposition genes analyzed (162 genes vs. 60 genes, respectively), nonetheless, they are concordant with the historical prediction of $10 \%$. These cohorts included a broad range of pediatric tumors from multiple centers in the United States and Europe. Importantly, there was overlap in the samples between these two studies.

Two additional pediatric pan-cancer studies sequenced patients with relapsed, refractory, or rare diseases, poor prognosis and/or a suspected CPS. Mody and colleagues identified 9.9\% (9/91) of patients with a cancer-related pathogenic germline finding. Of these, 4/9 patients had no remarkable family history of cancer. ${ }^{4}$ Comparatively, Oberg et al. found $20 \%(18 / 90)$ of patients in their study had a pathogenic germline mutation. Overall, $14 \%$ of their cohort had a mutation in a cancer predisposition gene. ${ }^{5}$ This study included analysis of the American College of Medical Genetics and Genomics (ACMG) secondary finding genes, a list of 59 medically actionable genes recommended by the ACMG to be returned to patients undergoing clinical sequencing, demonstrating the utility of these recommendations. ${ }^{45,46}$

As NGS continues to be utilized in the clinic, recommendations such as those described for return of secondary findings above, will be prudent when genetic test interpretation is not 
straight forward. ${ }^{45,46}$ In a group of relapsed/refractory tumors representative of 20 distinct noncentral nervous system (CNS) solid tumors, $11.8 \%$ (7/59) of patients had a pathogenic germline mutation in a known cancer predisposition gene, similar to previously discussed studies. Interestingly, one patient had a mutation in one allele each of TSC1 and TSC2 which would not be reportable alone, however, the researchers felt that together these data represented reportable findings. ${ }^{6}$ This demonstrates the complexity of interpreting germline mutations, in that genetic modifiers should be carefully considered.

Two small studies of patients at high risk for a CPS found a larger proportion of patients with pathogenic germline mutations than expected. The first analyzed patients with a CNS tumor and the following criteria: uncertain histological diagnosis, unsuccessful standard of care treatment, and/or disease that progressed through prior therapies. Of these patients, 35.5\% (11/31) had germline pathogenic mutations indicative of a CPS including Li-Fraumeni syndrome and Gorlin syndrome, some of whom had no family history. ${ }^{7}$ Similarly, a study of 40 children with cancer and at least one of the following features: intellectual disability and/or congenital anomalies, multiple primary cancers, positive family history, or adult cancer type, identified $20 \%$ (8/40) of patients carried a pathogenic germline mutation, 3 of which were pathogenic DICERI mutations. ${ }^{8}$ The samples in these studies were from small, high risk populations, and thus are likely an over-representation of CPS in pediatric cancer patients. However, they highlight the importance of considering a CPS in this group of patients and the utility of whole exome sequencing.

In comparison, Parsons et al. sequenced a cohort of patients with treatment naïve solid tumors to determine the diagnostic yield of clinical tumor and germline whole exome sequencing in this population. Ten percent $(15 / 150)$ of patients were found to have a pathogenic or likely pathogenic germline mutation, a similar estimate to other pan-cancer data. ${ }^{9}$ 
Lastly, certain subtypes of sarcoma are associated with CPS, such as osteosarcoma in LFS, and malignant peripheral nerve sheath tumors in neurofibromatosis type $1 .{ }^{40,47}$ However, recent sequencing data suggest a higher prevalence of CPS than expected in some subtypes. For example, whole exome sequencing of 1,004 patients with osteosarcoma found 28\% (281/1004) had a pathogenic germline mutation in a cancer predisposition gene, seven of which had not previously been associated with this type of cancer. ${ }^{48}$ Similarly, a recent case report described the first germline mutation in the DNA damage repair gene, $B A R D 1$, in a Ewing sarcoma patient. ${ }^{49}$ Ewing sarcomas are not within the spectrum of any known CPS, however, Brohl et al. sequenced 175 tumors and found $13.1 \%(23 / 175)$ of patients had pathogenic germline mutations in a cancer predisposition gene. ${ }^{50}$ As our knowledge of the genetic landscape of pediatric cancers continues to evolve, our definition of CPS-associated phenotypes and medically actionable genes may require revision.

The aforementioned sequencing studies suggest that generally, around $10 \%$ of pediatric cancers and as many as $35.5 \%$ of high-risk patients with CNS cancers are due to an underlying CPS. As NGS becomes a standard clinical tool, the phenotypic spectrum of well-characterized CPS will broaden and novel genotypic-phenotypic associations will continue to be identified. Together, the prevalence of pathogenic germline mutations in cancer predisposition genes and the identification of cancer survivors who are eligible for genetics follow up, suggest evaluation for a CPS may be warranted in more children with cancer than previously thought. ${ }^{44}$ 


\subsection{Barriers to Genetics Referrals}

CPS are underdiagnosed in children, as indicated by research carried out by genetics specialists. ${ }^{43,44}$ This suggests then, that in order to diagnose more children with a CPS, appropriate referrals to genetics providers with expertise in CPS must increase.

There are multiple ways in which a patient may access genetics services. The National Society of Genetic Counselors (NSGC) Service Delivery Model Task Force classified specific modes of referral as: traditional, tandem, triage, rescue, or self-referral. ${ }^{51}$ With the exception of self-referral, all entry points to genetics work-up require a non-genetics healthcare provider to

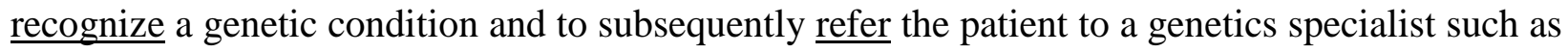
a genetic counselor or geneticist. Barriers to genetics referral have been well described in the literature with a focus on primary care and adult oncology practices and can be broadly classified as knowledge, evidence, and system barriers.

\subsubsection{Barrier: Provider Knowledge}

One of the most complex barriers to genetics referral is provider knowledge. This includes the provider's own genetics knowledge, confidence in explaining and managing patients based on genetics results, and knowledge of available genetic tests.

\subsubsection{Genetics Knowledge}

Qualitative and quantitative studies from around the world indicate physicians who do not specialize in genetics feel they lack sufficient knowledge of genetics as well as the confidence to

discuss such topics with their patients. ${ }^{24-26,29,52,53} \mathrm{~A}$ recent meta-analysis of perceived barriers to 
genetics services found that 22 out of the total 38 studies identified lack of physicians' genetics knowledge as a barrier to services. ${ }^{23}$ For instance, a survey of 82 physicians including PCPs, gynecologists, surgeons, and oncologists, found $67 \%$ felt more cancer genetics education would improve patient identification for cancer genetics referral. ${ }^{32}$ In a prenatal setting, the self-assessed clinical genetics knowledge of PCPs was a mean of 5, or moderate, on a scale of 0-10 (N=99). ${ }^{54}$ Further, Trinidad et al. found American PCPs not only lacked genetics knowledge, but were also concerned about the time it would take and the ease at which to access the most current information. ${ }^{26}$

Data collected from 1,427 physicians in Ontario, Canada found that while 91\% were aware of genetic testing available for hereditary breast and ovarian cancer, only $60 \%$ were aware of similar testing for hereditary colon cancer. Those with high confidence in genetics competencies, like family history taking and cancer risk assessment, were more likely to refer their patients for genetic counseling. When compared to oncologists, PCPs were less likely to refer patients for genetic evaluation, and similarly, of the physicians in the aforementioned Brandt et al. study, PCPs were significantly less comfortable identifying patients for genetics referral and discussing genetics with their patients than specialists. ${ }^{25,32}$ This discomfort has been described in qualitative interviews including a study of general practitioners (GPs) (the equivalent to American PCPs), in the UK that found some asked their patients to return at a later date once they had time to review important genetic information. ${ }^{29}$ Interviews of oncologists who had referred patients to The Michigan Oncology Sequencing Project at the University of Michigan, a paired tumor/normal genome sequencing research project with the goal of providing personalized oncology care, indicated assistance from a genetic counselor would be valuable for both the physician and the patient in clarifying results and their implications for care. ${ }^{55}$ These data are supported by a 
quantitative study of 363 Canadian physicians which found only $21 \%$ of family physicians, cardiologists and oncologists felt sufficiently informed about genetic testing in the context of precision medicine. ${ }^{56}$

As this research suggests, identification of genetic syndromes requires specialized knowledge. Whole exome sequencing of paired germline and pediatric tumors has provided examples of previously undiagnosed patients with a CPS who were diagnosed following sequencing. Parsons et al. identified $3 / 8$ patients not previously offered genetic testing but who possessed germline mutations in dominant cancer susceptibility genes associated with a childhood risk for cancer. One patient had a pathogenic $M S H 2$ mutation and a family history suggestive of Lynch syndrome. A thorough family history was not elicited during the patient's treatment for glioblastoma. The second patient had a plexiform neurofibroma, multiple anomalies, and a likely pathogenic germline $K R A S$ mutation and had not been clinically diagnosed with Noonan syndrome. Lastly, a patient with unilateral Wilms tumor was mosaic for a WT1 mutation and did not have typical congenital anomalies or developmental delay. ${ }^{9}$ These cases demonstrate both the clinical utility of NGS in oncology and the level of detailed knowledge required for diagnosis of some CPS including the importance of personal and family medical history information, and knowledge of complex genetics principles.

Knowledge about CPS has not been assessed in PCPs, pediatricians, or pediatric oncology HCP. Although the data above regarding physicians' knowledge about genetics are specific to adult oncology or primary care, they highlight a key issue with current referrals: genetics knowledge is essential to increase appropriate referrals for genetic evaluation but is currently lacking for non-genetics providers. The specific HCP required to be knowledgeable about CPS depends on patient presentation. Patients with a family history of a CPS may be identified by a 
PCP or pediatrician when they are asymptomatic, whereas pediatric hematologists/oncologists may identify symptomatic children. This suggests that various pediatric HCP should be considered when addressing knowledge about CPS and referral of these patients to genetics.

\subsubsection{Family History Information}

One aspect of genetics knowledge that is studied more specifically is the elicitation and quality of family history information. Multiple studies indicate that while PCPs gather family history information and appreciate its utility, it is unlikely to be complete. ${ }^{24,27,57,58}$ The majority (94.7\%) of American Academy of Pediatrics (AAP) members surveyed between 2013-2014 ( $\mathrm{N}=$ 349) indicated they believe family history information is important in determining disease risk and managing a patient's care. ${ }^{28}$ Yet an additional survey of American pediatricians and family doctors $(\mathrm{N}=448)$ indicated only $11 \%$ of respondents collected a full 3-generation history and only $2.8 \%$ reported constructing a pedigree. These researchers also found that participants gathered family history information using a linear rather than degree of relationship-focused approach. For example, while $66.7 \%$ of participants collected information on grandparents, $30.7 \%$ collected information on aunts and uncles even though both are second degree relations to the child. The researchers suggest the lack of information gathered on aunts and uncles may be insufficient to identify genetic conditions. ${ }^{27}$

For oncology patients, poor family history elicitation can result in missed or delayed referrals to genetics. A prospective study of 387 adult colorectal cancer patients compared selfreported patient histories with physician notes following an initial gastroenterology oncology clinic evaluation. The authors found $41 \%$ (127/311) of physician notes did not record a comprehensive family history of cancer. In fact, the more family members with cancer, the less

likely the physician was to take a more detailed family history. ${ }^{57}$ These data indicate the 
importance of accurate and thorough family history taking and illustrate familial gastrointestinal cancer risk was not appropriately assessed by oncologists.

A more recent study of oncology practices belonging to the American Society of Clinical Oncology's Quality Oncology Practice Initiative, demonstrated that family history information was incomplete (missing information on first- and second-degree relatives, and age at cancer diagnosis for those with cancer) for more than $60 \%$ of patients with breast or colorectal cancer. In addition, providers were less likely to elicit a complete family history or refer for genetic counseling/testing for patients with colorectal cancer compared to breast cancer. This trend continued even after accounting for differences between populations. ${ }^{22}$

In addition to the technique by which physicians gather family history information, barriers to a complete history identified by HCP include inadequate time during routine visits to collect or update information, inaccurate or incomplete information from patients, and increased disease complexity. ${ }^{24,28,53,57,59-61}$ In a pediatric oncology setting, there are additional challenges to family history elicitation due to the emotional effects of a pediatric cancer diagnosis, discussion of treatment plans and scheduling imaging appointments, and it is often deferred. ${ }^{1}$

The importance of family history information is emphasized by the association between personal and/or family history of cancer and higher likelihood of referral to a genetics specialist. ${ }^{19,62}$ A retrospective study in the United Kingdom (UK) aimed to describe the reasoning of GPs for referring an asymptomatic patient with a family history of cancer to a genetics clinic. Of the patients, $89 \%$ (63/71) reported they had initiated the discussion about their family history of cancer which led to the genetics referral. This was confirmed by the physicians. The most common reason patients initiated discussion was a recent cancer event in the family, yet only $20 \%$ (14/71) of patients recalled being asked details about their family history. Consistent with other 
research, the GPs felt a lack of knowledge in genetics, confidence in taking a detailed family history, and lack of patient knowledge hindered their ability to take a thorough family history. Furthermore, $69 \%(\mathrm{~N}=36)$ of the physicians in this study indicated a diagnostic clinic was the preferred referral route for asymptomatic patients unless the patient specifically asked for a referral to genetics. Ninety two percent of GPs did not know, or knew very little about the genetics clinic they referred to. ${ }^{24}$ This study again illustrates that PCPs lack appropriate genetics knowledge to ensure relevant information is collected, but also that genetics referrals for asymptomatic individuals with a family history of cancer are largely patient-driven.

While similar studies of pediatricians or pediatric oncologists could not be identified, a recent survey assessed parental attitudes to genetic counseling and/or testing. The group surveyed parents of children recently diagnosed with cancer and found that $64.3 \%(27 / 42)$ were familiar with genetic counseling and that 50\% (21/42) were interested in pursuing genetic counseling/testing but referral was not offered to $59.5 \%$ (25/42). ${ }^{63}$ Interest in genetic testing was not dependent on personal or family history of cancer or features suggestive of a CPS as described by Jongmans et al. ${ }^{11}$ Thus, the authors suggest that it is reasonable to consider referral to genetics for evaluation of a CPS despite family history in a pediatric oncology setting. ${ }^{63}$

Together, these data suggest genetics specialists are being underutilized whether due to the urgency of cancer treatment planning and disease management, or lack of genetics knowledge in the referring physician. While there is evidence to suggest that oncologists and other specialists feel more comfortable identifying patients at high risk for a CPS than PCPs, genetics specialists continue to identify these individuals in populations previously screened by other $\mathrm{HCP}$, indicating poor family history taking and/or over emphasis of a negative family history are barriers to genetics referrals. $^{43,44,56,57}$ 


\subsubsection{Barrier: Evidence}

Another barrier that is closely related to provider knowledge is evidence. This includes providers' understanding of the clinical utility of genetics information, as well as the use of tools designed to simplify and streamline genetics concepts.

\subsubsection{Perceived Clinical Utility}

There is qualitative evidence that suggests a physician's professional identity plays a role in resistance to including genetics as part of their practice in the UK. Twenty-one GPs were interviewed regarding their views on clinical genetics. Major themes that emerged included the distinction between family history taking and clinical genetics. One physician indicated genetics concepts did not "fit with GPs' thought processes". ${ }^{29}$ This theme indicates that while knowledge of genetics concepts may be lacking in GPs, more research and work needs to be done to stress the relevance of genetics as a whole to a GP or PCP's practice.

Interestingly, studies have shown that a number of physicians perceive a lack of therapeutic intervention for genetic conditions and thus feel it is inappropriate to collect such information from patients especially since it may cause anxiety. ${ }^{26,29}$ Further, some physicians do not refer patients for genetics evaluation because they believe it will not change patient management, or suspect genetic tests do not return meaningful results. ${ }^{30,64}$ While these data were collected over ten years ago, current studies suggest some physicians maintain these beliefs despite the growth and utilization of genomic medicine. A study of 157 practicing physicians from Texas found 56\% (88/157) reported genetics was slightly or not at all integral to patient care in their specialty. More specifically, $24 \%(8 / 34)$ of family or internal medicine physicians indicated genetics was moderately or very integral compared to $92 \%$ (24/26) of obstetricians/gynecologists. Further, $72 \%$ 
(113/157) of survey respondents rarely or never referred patients to genetic counseling which correlated with perceived importance. These data suggest the perceived value of genetics affects likelihood of genetics referral. ${ }^{65}$

Not surprisingly, most research in this field indicates PCPs and GPs find it difficult to keep up with genetics as a discipline, which contributes to their lack of confidence in providing patient

risk assessment, addressing ethical and legal concerns, and interpreting genetic test results. ${ }^{26,31,53}$ Genetics educational programs aimed at PCPs have been proven to increase knowledge and confidence of genetics topics. ${ }^{66}$ Nonetheless, a study of 24 PCPs in the US indicated a preference for "just-in-time" resources and educational programs that address "red flags" rather than comprehensive genetics training programs ${ }^{26}$ These data suggest that there is a lack of urgency to implement genetics into primary care practice, perhaps due to a misunderstanding of its importance.

\subsubsection{Tools}

Accessibility and utility of tools such as referral guidelines, and awareness of genetics services have the potential to improve appropriate genetics referrals. Many qualitative studies have indicated physicians felt clear, concise guidelines were lacking. ${ }^{24,28,29,57,67}$

Professional societies (American Cancer Society, ACMG/NSGC, American Association for Cancer Research, German Society for Pediatric Oncology and Hematology) and academic collaborations (McGill Interactive Pediatric OncoGenetic Guidelines) have established and continue to update practice guidelines for cancer predisposition assessment in order to standardize risk assessment criteria. ${ }^{14-17,68}$ All aim to provide concise, easy to understand guidelines to identify pediatric and/or adult oncology patients at risk for a CPS who should be referred for genetic consultation. 
Despite these efforts, evidence indicates that referral rates for adult patients who meet published guidelines for referral to a cancer genetics clinic vary widely between 22-68\%. Referrals are more likely for patients cared for in academic versus community centers, patients with breast cancer rather than gynecologic or colorectal cancer, closer geographical distance to the care center, and non-African American race. ${ }^{18-22}$

Some research suggests that lack of adherence to guidelines is closely related to genetics knowledge and perceived clinical utility of genetic counseling or genetic testing. One survey of gastroenterologists found that while $79 \%$ of physicians appropriately identified a pedigree suspicious for Lynch syndrome, only $16 \%$ recommended the correct screening based on published guidelines and only $34 \%$ of respondents were aware that genetic testing for Lynch syndrome was available. Those who did not recommend genetic testing for the proband were more likely to agree that genetic testing is not beneficial. In addition, $48 \%$ of respondents were unaware that genetic testing for familial adenomatous polyposis (FAP) was available. ${ }^{69} \mathrm{FAP}$ is a CPS that includes risks for childhood cancer such as hepatoblastoma and colon cancer. Individuals with FAP may begin cancer surveillance in infancy or childhood if a mutation is identified, illustrating the importance of genetic testing in these individuals. ${ }^{70}$ Another study of adults with colorectal cancer found that 19\% (75/387) of patients met Bethesda guidelines for assessment for Lynch syndrome, a CPS with adult onset cancers, however only 17\% (13/75) of eligible individuals were referred for genetic evaluation. ${ }^{57}$ While there have been advancements in genetics education since these studies were completed, they nonetheless indicate a lack of understanding of CPS, lack of adherence to established guidelines, and fewer referrals to genetics professionals which may affect cancer surveillance and mortality for at-risk individuals. ${ }^{71}$ 
Some clinics have addressed these issues by embedding genetic counseling services within adult oncology clinics or providing toolkits to aid in identifying appropriate referrals, both of which have been successful. ${ }^{62,72-74}$ In the adult oncology setting, interventions such as the introduction of a genetics referral toolkit demonstrate that education does increase genetics referrals. Beginning in 2014, the National Comprehensive Cancer Network and the Society of Gynecologic Oncology began to recommend genetic counseling and consideration of genetic testing for women with epithelial ovarian cancer (EOC) at any age. ${ }^{75,76}$ In a historical cohort of 81 women with EOC seen at Mayo Clinic Rochester between July 1, 2013 and December 31, 2013, less than half (39/81) were referred for genetics consultation. The consensus guidelines as well as the implementation of a referral toolkit that consisted of a referral template, genetic risk checklist, and family history worksheet as well as education sessions for medical oncology, gynecologic surgery, and genetics professionals increased the referral rate of new patients by $26.1 \%{ }^{62}$

Some gynecological cancer clinics have integrated genetic counselors into their practice increasing the visibility and availability of genetics services for women with ovarian cancer. American and Australian groups have reported an increased uptake of services and guideline compliance. ${ }^{72,73}$ More specifically, the American study found a $46 \%$ increase (38\% preintervention to $84 \%$ post-intervention) in genetic counseling appointments following the placement of a genetic counselor in the clinic which was consistent even on days when the genetic counselor was not physically present. ${ }^{72}$ Similarly, the Australian group found referrals increased from $54 \%$ pre-intervention to $85 \%$ post-intervention. ${ }^{73}$

While the model for these interventions is simplified in that guidelines state all women with ovarian cancer be referred for genetic evaluation, genetics education and multidisciplinary 
care teams that include genetic counselors increase referrals. These principles may be applied in the pediatric oncology setting as well.

\subsubsection{Barrier: System}

Physicians with the knowledge and tools to suspect a patient has a CPS may still encounter system barriers to referral. A survey of American PCPs in the early 2000s indicated 67\% ( $\mathrm{n}=190)$ felt accessibility to face-to-face genetics consultation was difficult or unavailable. Similarly, $58 \%$ felt accessibility to remote genetics consultation was difficult or unavailable. Respondents were asked to estimate the proportion of visits in which they discussed a genetic condition and the subsequent proportion that resulted in referral to genetics. For each condition discussed, less than half were referred. Patients with congenital anomalies were referred by almost half of physicians (48\%) which theoretically may have included some CPS relevant in childhood. Patients with a family history of breast and/or ovarian cancer were referred by $14 \%$ of physicians, whereas those with a family history of colon cancer were referred by $7 \% .{ }^{31}$ While the quantification of these referrals is likely subject to recall bias due to study design, this work suggests accessibility to genetics services is a major factor in referral practices for PCPs. Other barriers identified by respondents were patient concerns, or ethical/social issues which included unclear guidelines. ${ }^{31}$

\subsubsection{Accessibility}

Many aspects of the referral process may reduce accessibility. In the adult oncology setting, a national survey of PCPs, internal medicine, and obstetrics and gynecology specialists found that $45.9 \%(365 / 795)$ of physicians did not refer patients for genetics evaluation when a CPS was suspected. While inconvenient location of referral was a reason not to refer for $22.7 \%(83 / 365)$ of 
physicians, $24.6 \%(90 / 365)$ were unaware of the method by which to refer patients. Stratification of responses by referral preference indicated that physicians located further than 10 miles from a genetic counselor were less likely to refer (68.7\%), suggesting that location as well as knowledge of the referral process creates a barrier to genetics referral. The two most common reasons for not referring patients with a suspected CPS to genetics were uncertainty of which patients to refer (38.3\%) and concerns about cost (37.2\%). Only 9\% (33/365) of physicians indicated they would initiate testing themselves, and another 9.3\% (34/365) felt genetics information was not useful in patient management, suggesting a significant number of patients in whom a CPS was suspected would not appropriately be followed or managed. ${ }^{30}$

Some studies have documented that shorter geographic distance to a genetic counselor or academic center is more likely to result in referral for genetic assessment in an adult oncology setting. Retrospective analysis of 696 women diagnosed with epithelial ovarian cancer at the University of Virginia between 2004 and 2015 found that living more than 100 miles away from a genetics center was less likely to result in referral (OR 0.49; 95\% CI 0.28-0.86) compared to 50 miles away or less. A distance of 50-100 miles from a genetics center was not significantly different from less than 50 miles (OR 0.72; 95\% CI 0.46-1.15). The authors point out that although guidelines changed to recommend genetics referral for all women diagnosed with EOC during the study period, a third of women were still not being referred 2 years following the introduction of these guidelines. ${ }^{19}$ Therefore, despite professional guidelines, a large proportion of women were not being referred appropriately, and proximity to a facility that provides genetics services is a possible contributing factor.

In the pediatric setting, professional guidelines recommend genetics evaluation for children with developmental delay. In Alabama, 43\% (59/137) of pediatricians surveyed referred to 
genetics as the first step in their evaluation. Distance to a genetics center was a reason not to refer for only $12 \%$ (16/137), indicating a difference in approach compared to adult oncology. In fact, physicians who practiced further than 100 miles away from a genetics center were more likely to refer patients (53\%) compared to those between 50-100 miles (24\%) and less than 50 miles $(38 \%) \cdot{ }^{64}$ While this and the study by Acheson et al. did not directly compare indications and the likelihood of referral for genetics evaluation, these data suggest pediatric patients are more likely to be referred to genetics for visible concerns rather than theoretical risks such as a family history of cancer. ${ }^{31}$

Accessibility to genetics professionals impacts the likelihood that patients with genetic conditions will be referred. In an adult oncology setting, close proximity to a genetics center is more likely to result in referral, however, knowledge and evidence factors including the improper use of professional guidelines also contribute to inaccessibility. In contrast, in pediatrics, there is evidence to suggest that the further the distance, the more likely the child will be referred. It is unclear how these factors contribute when assessing children for a CPS.

\subsubsection{Cost}

Multiple studies have cited that lack of insurance coverage or cost for genetic services is a barrier to genetics referrals. ${ }^{30-32,64,67}$ As described above, the second most common reason physicians indicated they would not refer a patient for genetic counseling was cost $(136 / 365$, $37.2 \%) .{ }^{30}$ Similarly, of 82 PCPs and specialist physicians surveyed regarding their referral practices to a cancer genetics program, approximately $33 \%$ were unaware that testing laboratories accept insurance and that approval is not uncommon. ${ }^{32}$ Another survey of 1,251 physicians including PCPs, tertiary care physicians, and oncologists indicated 59.8\% agreed with the statement that genetic tests for CPS are not usually covered by patients' health plans ${ }^{67}$ While this 
study addresses genetic testing rather than genetic counseling or referral to a genetics specialist, the results suggest cost is a relevant concern for many providers.

Cost is also a concern for patients. A retrospective study of women who had received genetic counseling and cancer risk assessment from a cancer center in Arizona between 2002 and 2004, found that insurance coverage and lower cost of genetic testing were significant predictors of test uptake. ${ }^{77}$ Women with breast or ovarian cancer identified through the Utah Cancer Registry also indicated test costs and insurance coverage were reasons for delayed uptake or declined testing $(38.9 \%, \mathrm{n}=142) \cdot{ }^{78}$ While these studies focused on women who obtained genetic counseling, they indicate that cost and insurance coverage factor into patient as well as physician decision-making in the context of genetics services.

\subsection{Summary}

Early diagnosis of a CPS and subsequent cancer surveillance improves patient outcomes. Furthermore, diagnosis of an individual may lead to diagnosis of other family members. In this way, identifying patients with an underlying CPS and utilizing preventative care measures improves public health. Knowledge, evidence, and systems barriers to genetics referral for evaluation of a CPS are prevalent and described in the literature as it pertains to adult oncology or general pediatrics. There is a lack of research focused on the referral practices of pediatric oncologists to genetics programs for evaluation of childhood onset CPS. The goal of this study is to address this gap in knowledge by surveying American healthcare providers involved in the care of pediatric oncology patients. 


\subsection{Manuscript}

\subsection{Background}

Cancer predisposition syndromes (CPS) are caused by pathogenic germline mutations in tumor suppressor genes, or more rarely oncogenes, which confer an increased lifetime risk for cancer. Historical data predicted $10 \%$ of all pediatric cancers were due to a CPS. ${ }^{1,10}$ Empirical data now suggest $7.6-35.5 \%$ of childhood cancers are due to an underlying CPS. ${ }^{2-9}$ Even so, retrospective studies of childhood cancer survivors have identified children that are eligible for genetic evaluation or meet clinical disease criteria. ${ }^{42,44}$ Furthermore, extrapolation of CPS prevalence data to childhood cancer survivors predicts $11.8 \%$ carry a pathogenic germline mutation in a cancer predisposition gene. ${ }^{79}$ While the proportion of individuals with a CPS varies based on tumor type, study population, and classification of mutations, these data illustrate that overall, CPS are underdiagnosed in the pediatric population.

Individuals with a CPS are at an increased risk to develop treatment toxicity and secondary tumors, and thus benefit from early diagnosis, which may inform management and surveillance. ${ }^{10-}$ ${ }^{13}$ Diagnosis of a CPS may occur in symptomatic individuals following a personal history of cancer, or asymptomatic individuals following identification of a CPS in the family. To facilitate the identification of patients with a suspected CPS, referral guidelines have been established. ${ }^{14-17}$ Rates of genetic referral uptake for pediatric oncology patients are unknown but can be inferred from studies in adult oncology. Genetic referral uptake rates range from $22-68 \%$ in this setting, and vary based on physician and patient factors. ${ }^{18-22}$ 
Numerous barriers to genetics referrals have been identified in the primary care and adult oncology literature and can be broadly categorized as knowledge, evidence, and system barriers. Research suggests that providers feel they do not possess the specialized knowledge or confidence required to discuss genetic conditions with their patients, and some physicians believe additional cancer genetics education would improve patient identification for cancer genetics referral. ${ }^{24-}$ $26,32,52,53$

Despite professional guidelines to aid in identification of patients appropriate for referral, some healthcare providers (HCP) perceive genetic services lack clinical utility and are not integral to their practice. ${ }^{30,64,65}$ Unsurprisingly, this perception has been linked to lack of genetics knowledge and adherence to guidelines. ${ }^{65,69}$ Although PCPs have indicated it is difficult to keep up with genetics as a discipline, which contributes to their lack of confidence, they prefer abbreviated resources rather than comprehensive genetics training programs. ${ }^{26,31,53}$

System barriers to genetics referral include access to genetics services and/or professionals. In adult oncology, further distance from a genetic counselor or genetics clinic has been correlated with decreased referral likelihood for CPS evaluation. ${ }^{19,30}$ In addition, some research suggests that the referral process itself may be a hinderance, as many PCPs are unaware of which clinic to refer to or how to initiate the process. ${ }^{24,25,30}$ Cost has also been considered a barrier to genetics referral by the HCP and uptake by the patient. ${ }^{30-32,80}$

Given that most research on the topic of barriers to genetics referrals focuses on data from primary care and adult oncology, this study investigates current referral practices of $\mathrm{HCP}$ involved in the care of pediatric oncology patients with a suspected CPS. We surveyed members of the Children's Oncology Group (COG) to understand how they currently assess patients for genetics referral, and what barriers they perceive to this process. 


\subsection{Methods}

\subsubsection{Recruitment}

An electronic survey link was emailed to 3,219 physicians who were active members of COG and who indicated their specialty was hematology/oncology, surgery, pathology, cellular therapy, or cytogenetics. In total, 230 responses were returned. Forty-one responses were excluded because they were incomplete. The total number of complete responses was 189 . The response rate was $5.8 \%$.

Eligible participants were healthcare providers involved in pediatric oncology care located in the United States. All responses were anonymized. Participants were encouraged to forward the survey link to their eligible colleagues. Responses were recorded February 5, 2020 - March 2, 2020. A reminder was sent one week prior to closure of the survey. This study was approved by the University of Pittsburgh Institutional Review Board as an exempt protocol (STUDY19090002) (Appendix B).

\subsubsection{Survey Design}

The survey consisted of six sections: demographics, family history, barriers, knowledge, accessibility, and genetic testing. The demographics section included questions about the participant and details about their practice. The family history section asked respondents how they collect family history information. The barriers section included questions about perceived barriers to family history collection and referrals. Questions about specific cancer types and features of CPS were part of the knowledge section. The accessibility section included questions about access 
to genetics providers, use of referral guidelines, and access to other genetics services. The genetic testing section asked respondents about current genetic testing practices and comfort with genetic test results. Questions were modeled after published surveys distributed to other medical specialties or designed by the authors to address gaps in knowledge. Some questions allowed respondents to select multiple answers. The survey was piloted before distribution by E.K., K.M.B., R.G., and J.M. to ensure questions were relevant, straight forward, free of errors, and to ensure flow. It was administered using the Qualtrics survey platform accessed through a University of Pittsburgh license. The survey can be found in Appendix D.

\subsubsection{Statistical Analysis}

Data were analyzed by descriptive statistics. Totals vary by question as some questions allowed respondents to select all choices that apply. Proportion of response was calculated based on the number of total responses for each individual question. Pearson's $\chi^{2}$ test was used to assess relationships between guideline use and demographic factors. Z-test for proportions was used to compare guideline use and Likert scale questions. Analyses were performed with Stata (v.16).

\subsection{Results}

\subsubsection{Demographics}

Participant demographic data are summarized in Table 1 . The majority of respondents were staff physicians $(80.4 \%, 152 / 189)$, other respondents were MD/DO fellows (15.3\%, 29/189), PhDs 
$(7.4 \%, 14 / 189)$, or a genetic counselor $(0.5 \%, 1 / 189)$. Of those participants who possessed a $\mathrm{PhD}$, 13/14 were also MDs.

The majority of respondents identified their specialty as hematology/oncology $(70.4 \%$, 131/186). Additional specialties included surgery $(7.5 \%, 14 / 186)$, pediatrics $(3.8 \%, 7 / 186)$, pathology $(1.6 \%, 3 / 186)$, genetics $(0.5 \%, 1 / 186)$, or other $(3.8 \%, 7 / 186)$. Those participants who chose other indicated specialties in ophthalmology, pediatric urology, subspecialties of oncology (orthopedic oncology, neuro-oncology), or multiple specialties such as genetics and oncology.

Over half of respondents were between 30-49 years old $(67.7 \%, 126 / 186)$. Almost a quarter $(24.3 \%, 45 / 185)$ of respondents have been practicing for less than five years. Similarly, $23.2 \%$ (43/185) have practiced for over 20 years, with the remaining participants practicing between 510 years $(20 \%, 37 / 185), 11-20$ years $(19.5 \%, 36 / 185)$, or currently training $(24 / 185,13 \%)$. There was representation from each major region of America, though some states did not have a single respondent.

The most common practice settings were children's hospitals within an academic center $(55.7 \%, 108 / 194)$, followed by freestanding children's hospital $(40.2 \%, 78 / 194)$. Others indicated their primary practice setting was part of a cancer center $(2.1 \%, 4 / 194)$, private $(1.5 \%, 3 / 194)$, or did not fit into the above categories $(1.0 \%, 2 / 194)$. The size of each practice was estimated by clinical volume of new pediatric oncology patients per year. Most participants indicated a clinical volume of less than 100 patients $(42.8 \%, 80 / 187)$ or $100-250$ patients $(36.9 \%, 69 / 187)$. Respondents were asked to estimate what proportion of patients seen in their clinic have a diagnosed CPS. These estimates were comparable to the known CPS population prevalence of approximately $10 \%$. Those respondents who indicated more than $10 \%$ of their patients had a diagnosed CPS $(6.5 \%, 12 / 186)$ practiced within a cancer predisposition clinic. 
Table 1. Demographic characteristics of survey respondents.

\begin{tabular}{|c|c|c|}
\hline Characteristic & Number & (\%) \\
\hline \multicolumn{3}{|l|}{ Level of training } \\
\hline MD (staff physician) & 152 & 80.4 \\
\hline MD/DO (fellow) & 29 & 15.3 \\
\hline $\mathrm{PhD}$ & 14 & 7.4 \\
\hline Genetic counselor & 1 & 0.5 \\
\hline \multicolumn{3}{|l|}{ Specialty } \\
\hline Hematology/oncology & 131 & 70.4 \\
\hline Surgery & 14 & 7.5 \\
\hline Pediatrics & 7 & 3.8 \\
\hline Pathology & 3 & 1.6 \\
\hline Genetics & 1 & 0.5 \\
\hline Other & 7 & 3.8 \\
\hline \multicolumn{3}{|l|}{ Age } \\
\hline$\leq 30$ & 3 & 1.6 \\
\hline $30-39$ & 72 & 38.7 \\
\hline $40-49$ & 54 & 29.0 \\
\hline $50-59$ & 33 & 17.7 \\
\hline $60-69$ & 20 & 10.8 \\
\hline$\geq 70$ & 4 & 2.2 \\
\hline \multicolumn{3}{|l|}{ Years in practice } \\
\hline Currently training & 24 & 13.0 \\
\hline Less than 5 & 45 & 24.3 \\
\hline $5-10$ & 37 & 20.0 \\
\hline $11-20$ & 36 & 19.5 \\
\hline $20+$ & 43 & 23.2 \\
\hline \multicolumn{3}{|l|}{ Practice location } \\
\hline Northeast (CT, ME, MA, NH, NJ, NY, PA, RI, VT) & 37 & 20.1 \\
\hline Midwest (IA, IL, IN, KS, MI, MN, MO, NE, ND, OH, SD, WI) & 45 & 24.5 \\
\hline South (AL, AR, DC, DE, FL, GA, KY, LA, MD, MS, NC, OK, SC, TN, TX, VA, WV) & 71 & 38.6 \\
\hline West (AK, AZ, CA, CO, HI, ID, MT, NV, NM, OR, UT, WA, WY) & 31 & 16.8 \\
\hline \multicolumn{3}{|l|}{ Practice setting } \\
\hline Children's hospital within academic/university center & 108 & 55.7 \\
\hline Freestanding children's hospital & 78 & 40.2 \\
\hline Cancer Center & 4 & 2.1 \\
\hline Private practice & 3 & 1.5 \\
\hline Other & 2 & 1.0 \\
\hline \multicolumn{3}{|l|}{ Clinical volume (new pediatric oncology patients) } \\
\hline Less than 100 & 80 & 42.8 \\
\hline $100-250$ & 69 & 36.9 \\
\hline More than 250 & 35 & 18.7 \\
\hline Not currently seeing patients & 3 & 1.6 \\
\hline \multicolumn{3}{|l|}{ Proportion of patients with diagnosed CPS } \\
\hline None & 2 & 1.1 \\
\hline Less than $5 \%$ & 81 & 43.5 \\
\hline $5-10 \%$ & 65 & 34.9 \\
\hline More than $10 \%$ & 12 & 6.5 \\
\hline Unsure & 26 & 14.0 \\
\hline
\end{tabular}




\subsubsection{Access to Genetics Services}

Access to genetics professionals or a cancer predisposition clinic was elucidated to determine whether an association with referral attitudes existed. Greater than half $(59.7 \%$, 108/181) of respondents indicated their institution had a cancer predisposition clinic, with $70.8 \%$ (75/108) situated within the pediatric hematology/oncology division (Table 2). Furthermore, 97.3\% (182/187) indicated they had access to a genetics specialist including a geneticist or genetic counselor. A large majority $(87 \%, 160 / 184)$ of participants reported they consult with genetics or CPS specialists if they suspect a patient has a CPS. Feedback from the genetics clinic regarding referral appropriateness was common for $62.6 \%$ (114/182) of respondents. Some participants received feedback before referral at tumor board meetings or during consultations. Respondents were also asked to specify the sources through which they obtain information about genetics; scientific literature $(95.2 \%, 177 / 186)$ and personal communication with genetics professionals $(82.3 \%, 153)$ were the most common. 
Table 2. Access to genetics services.

\begin{tabular}{|c|c|c|}
\hline & Number & $(\%)$ \\
\hline \multicolumn{3}{|l|}{ Institution has cancer predisposition clinic } \\
\hline Yes & 108 & 59.7 \\
\hline Hematology/oncology & 75 & 70.8 \\
\hline Medical genetics & 25 & 23.6 \\
\hline Other & 8 & 7.5 \\
\hline No & 60 & 33.1 \\
\hline Unsure & 13 & 7.2 \\
\hline \multicolumn{3}{|l|}{ Access to a genetics specialist } \\
\hline Yes & 182 & 97.3 \\
\hline Geneticist & 152 & 83.5 \\
\hline Certified genetic counselor & 162 & 89.0 \\
\hline \multicolumn{3}{|l|}{ Other } \\
\hline Oncologist with expertise in CPS & 9 & 4.9 \\
\hline Molecular program & 3 & 1.6 \\
\hline No & 5 & 2.7 \\
\hline \multicolumn{3}{|l|}{ Consult with a genetics specialist if suspect a CPS } \\
\hline Yes & 160 & 87.0 \\
\hline No & 4 & 2.2 \\
\hline Sometimes & 18 & 9.8 \\
\hline $\mathrm{N} / \mathrm{A}$ & 2 & 1.1 \\
\hline \multicolumn{3}{|l|}{ Receive feedback from a genetics clinic regarding referrals } \\
\hline Yes & 114 & 62.6 \\
\hline No & 48 & 26.4 \\
\hline Unsure & 20 & 11.0 \\
\hline \multicolumn{3}{|l|}{ Participate in molecular/genetics tumor boards } \\
\hline Yes & 86 & 46.5 \\
\hline No, but occur within institution & 59 & 31.9 \\
\hline No, there are none within institution & 40 & 21.6 \\
\hline \multicolumn{3}{|l|}{ Sources used to obtain information about genetics } \\
\hline Scientific literature & 177 & 95.2 \\
\hline Fellowship/training & 116 & 62.4 \\
\hline CME activities & 76 & 40.9 \\
\hline Personal communication with genetics professionals & 153 & 82.3 \\
\hline Multi-disciplinary tumor board meeting & 141 & 75.8 \\
\hline
\end{tabular}

\subsubsection{Referral Practices}

To investigate current referral practices, participants were asked who the most appropriate provider is to refer a patient with a CPS for genetics evaluation. The majority of respondents believed a hematologist/oncologist was most appropriate $(83.9 \%, 151 / 180)$, whereas $5.6 \%$ 
(10/180) thought a medical geneticist was most appropriate (Table 3). Conversely, participants felt medical geneticists $(62 \%, 111 / 179)$ were the most appropriate provider to diagnose a patient with a CPS, whereas $19.6 \%$ (35/179) thought hematologists/oncologists and 12.8\% (23/179) thought genetic counselors were most appropriate to diagnose.

Respondents indicated that they rarely $(42.6 \%, 78 / 183)$ or sometimes $(30.1 \%, 55 / 183)$ referred patients for a CPS evaluation. Fewer than a quarter of respondents often $(18.6 \%, 34 / 183)$ or frequently $(2.7 \%, 5 / 183)$ referred patients for a CPS evaluation. Frequency was not correlated with use of referral guidelines.

Formal referral guidelines were used always $(34.2 \%, 63 / 184)$ or sometimes $(34.8 \%$, $64 / 184)$ and most respondents were somewhat $(44.4 \%, 56 / 126)$ or extremely $(15.9 \%, 20 / 126)$ satisfied with the guidelines they use, while 32.5\% (41/126) were indifferent. A quarter of participants (45/180) did not use the same guidelines as their colleagues, and 58.9\% (106/180) were unsure of which, if any, guidelines their colleagues used. Use of guidelines was dependent on clinical volume of CPS patients (Pearson's $\chi^{2}, \mathrm{p}=0.01$ ).

The main reason for not using guidelines was the lack of guideline availability (34.4\%, 45/131), with an additional 8.4\% (11/131) who were unaware guidelines existed. About a quarter (32/131) of participants felt confident referring without guidelines, and 15.3\% (20/131) indicated conflicting guidelines from different sources discouraged their use. Other responses included the use of formal institutional guidelines (5/131), respondent considered another provider more appropriate to assess the patient (5/131), referral of all pediatric oncology patients to genetics (4/131), inconsistent application of guidelines (3/134), or unclear guidelines, lack of time to use guidelines, or still training (2/134). 
Table 3. Referral practices.

\begin{tabular}{|c|c|c|}
\hline & Number & $(\%)$ \\
\hline \multicolumn{3}{|l|}{ Most appropriate provider to refer for CPS evaluation } \\
\hline Hematologist/Oncologist & 151 & 83.9 \\
\hline Medical geneticist & 10 & 5.6 \\
\hline Genetic counselor & 8 & 4.4 \\
\hline Primary care physician & 2 & 1.1 \\
\hline Other & 9 & 5.0 \\
\hline \multicolumn{3}{|l|}{ Most appropriate provider to diagnose CPS } \\
\hline Hematologist/Oncologist & 35 & 19.6 \\
\hline Medical geneticist & 111 & 62.0 \\
\hline Genetic counselor & 23 & 12.8 \\
\hline Pathologist & 1 & 0.6 \\
\hline Other & 9 & 5.0 \\
\hline \multicolumn{3}{|l|}{ Referral frequency for CPS } \\
\hline Frequently (several times per week) & 5 & 2.7 \\
\hline Often (several times per month) & 34 & 18.6 \\
\hline Sometimes (once per month) & 55 & 30.1 \\
\hline Rarely (a few times per year) & 78 & 42.6 \\
\hline Never & 7 & 3.8 \\
\hline N/A & 4 & 2.2 \\
\hline \multicolumn{3}{|l|}{ Use guidelines } \\
\hline Yes & 63 & 34.2 \\
\hline No & 57 & 31.0 \\
\hline Sometimes & 64 & 34.8 \\
\hline \multicolumn{3}{|l|}{ Satisfaction with current guidelines } \\
\hline Extremely satisfied & 20 & 15.9 \\
\hline Somewhat satisfied & 56 & 44.4 \\
\hline Neither satisfied nor dissatisfied & 41 & 32.5 \\
\hline Somewhat dissatisfied & 8 & 6.3 \\
\hline Extremely dissatisfied & 1 & 0.8 \\
\hline \multicolumn{3}{|l|}{ Providers within practice use the same guidelines } \\
\hline Yes & 29 & 16.1 \\
\hline No & 45 & 25.0 \\
\hline Unsure & 106 & 58.9 \\
\hline \multicolumn{3}{|l|}{ Main reason not using guidelines } \\
\hline Lack of available guidelines & 45 & 34.4 \\
\hline Conflicting guidelines from different sources & 20 & 15.3 \\
\hline Feel confident in referring without them & 32 & 24.4 \\
\hline Other & 34 & 25.4 \\
\hline Unaware of guidelines & 11 & 8.4 \\
\hline Use institutional guidelines & 5 & 3.8 \\
\hline Other provider more appropriate & 5 & 3.8 \\
\hline Refer all & 4 & 3.1 \\
\hline Not always applicable & 3 & 2.3 \\
\hline Require clarification & 2 & 1.5 \\
\hline Time & 2 & 1.5 \\
\hline Still learning & 2 & 1.5 \\
\hline
\end{tabular}


To elucidate the type of patients that participants may consider referring for evaluation of a CPS, they were asked how often they refer a patient with a given cancer for assessment. The list included cancers with different levels of recommendation for referral based on published guidelines. Of the cancer types recommended to result in referral regardless of family history, or other features suggestive of a CPS, pheochromocytoma/paraganglioma (PPGL) and choroid plexus carcinoma (CPC) were the most likely to always result in referral, however, this was only indicated by $31.3 \%$ (51/163) and 29.4\% (47/160) of respondents (Figure 1A). Current guidelines suggest all cases of PPGL or CPC should be referred for assessment. Participants who used guidelines were significantly more likely to always refer a patient with PPGL (one tailed z-test, $\mathrm{p}<0.05)$.

The majority of respondents indicated they rarely refer patients with medulloblastoma, osteosarcoma, embryonal/alveolar rhabdomyosarcoma, glioma, neuroblastoma, Wilms tumor, acute myeloid leukemia, or Ewing sarcoma. Most respondents also specified they rarely referred patients with Hodgkin lymphoma, a cancer that is often sporadic, for genetics referral. Hodgkin lymphoma was included to ensure the internal validity of the question.

We then assessed the likelihood that a patient would be referred for evaluation of a CPS if they presented with a malignancy and additional features. Features were previously described by Jongmans et al. to be suggestive of a pediatric CPS and warrant referral to genetics. ${ }^{11}$ While the majority of respondents were likely to refer patients with each concerning feature, the certainty with which they did so varied. Well understood indications were extremely likely to be referred, such as a patient with a malignancy and genetic test results indicating a germline mutation in a cancer predisposition gene $(89.1 \%, 164 / 184)$ or multiple malignancies $(85.9 \%, 158 / 184)$ (Figure 1B). In contrast, a patient presenting with a malignancy and developmental delay/intellectual 
disability was extremely likely to be referred by only $12.5 \%(23 / 184)$ of respondents, with most somewhat likely $(45.1 \%, 83 / 184)$ or neither likely nor unlikely $(34.2 \%, 63 / 184)$ to refer for genetic evaluation indicating physician uncertainty despite published guidelines that recommend referral for these indications. ${ }^{11,14,17}$

When familiarity with published guidelines for referral/evaluation of a CPS was used to stratify responses, those who did not use guidelines were significantly less likely to refer patients with a malignancy and immune deficiency (one tailed z-test, $\mathrm{p}<0.05$ ). Overall likelihood to refer patients with other features were not associated with guideline use, however tendency (extremely vs somewhat likely or unlikely) was significantly associated for some features. Patients with features of abnormal growth such as macrocephaly, or hemihyperplasia were extremely likely to be referred by $41.2 \%(52 / 126)$ of respondents who used referral guidelines compared to $23.6 \%$ $(13 / 55)$ of respondents who did not use referral guidelines (one tailed $z$-test, $\mathrm{p}<0.05$ ). Those participants who did not use guidelines still indicated they were somewhat likely to refer patients with abnormal growth $(60 \%, 33 / 55)$. A similar trend was observed for the patients with excessive toxicity to cancer therapy; $23.8 \%(30 / 126)$ of respondents who use guidelines were extremely likely to refer compared to $10.9 \%(6 / 55)$ of those who do not use guidelines (z-test, $\mathrm{p}<0.05)$. These data suggest that guideline use increases confidence in appropriate referrals. 

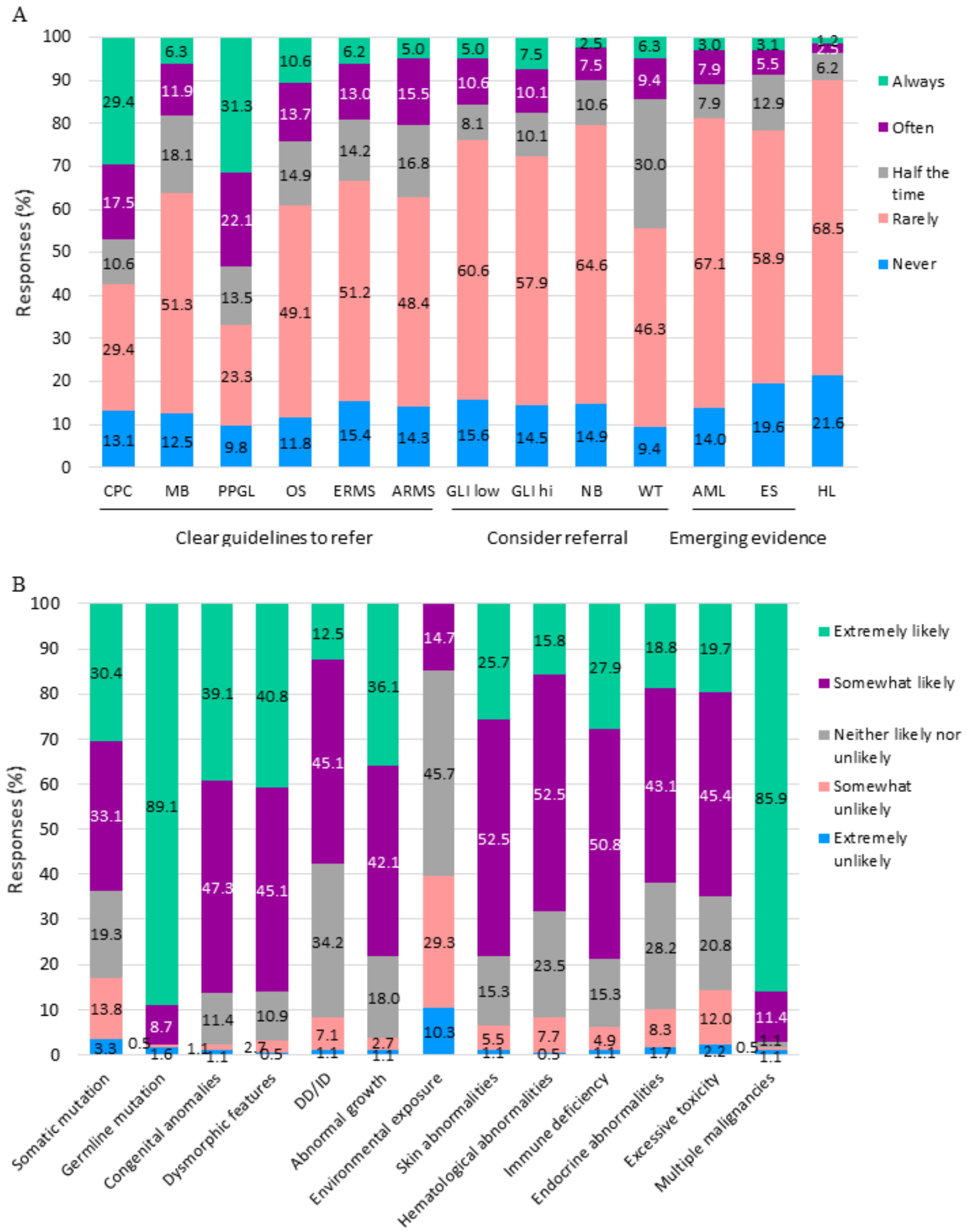

Figure 1. Likelihood to refer for CPS evaluation. A. Likelihood of respondents to refer a patient for evaluation of a CPS based on disease type. B. Likelihood of respondents to refer a patient for evaluation of a CPS based on features 
as decribed by Jongmans et al. ${ }^{11}$ Abbreviations: CPC choroid plexus carcinoma, MB medulloblastoma, PPGL pheochromocytoma/paraganglioma, OS osteosarcoma, ERMS embryonal rhabdomyosarcoma, ARMS alveolar rhabdomyosarcoma, GLI glioma, NB neuroblastoma, WT Wilms tumor, ES Ewing sarcoma, HL Hodgkins lymphoma, DD/ID developmental delay/intellectual disability.

\subsubsection{Family History Elicitation}

Family history was considered essential to assessment of new pediatric oncology patients by greater than $90 \%$ of respondents regardless of whether or not a CPS was suspected (Appendix A, Table 1). However, research suggests that adult oncologists do not collect complete family history information. To investigate whether this applies to pediatric health care providers, we asked respondents to indicate the frequency with which they ask about particular family members when eliciting family history for a routine pediatric oncology patient or a pediatric oncology patient with a suspected CPS (Table 4). Regardless of evaluation type, almost all respondents always collect information about the patient's mother, father, and full siblings (routine pediatric oncology patient 96\%, or suspected CPS 98\%). Participants were more likely to always ask about distantly related individuals if the patient was suspected to have a CPS, however, aunts/uncles and half siblings were asked about less often than grandparents despite the same degree of relationship to the patient. Grandparents were always included by $82.9 \%$ (150/181) of participants taking a family history for a routine patient whereas aunts/uncles were included by $57 \%$ (101/178).

Since some evidence has found childhood cancer survivors may be eligible for genetic assessment and/or may have an underlying CPS, we asked how often respondents reviewed the family history. For most routine patients, family history was reviewed only if the patient mentioned an update $(58.1 \%, 108 / 186)$ but if the patient was suspected to have a CPS, family history was reviewed most of the time $(40.9 \%, 74 / 181)$. Some respondents specified time points (every 3-6 
months, annually) for family history review, or indicated family history elicitation was outside of their scope of practice (ex. pathologists).

Table 4. Family history assessment.

\begin{tabular}{lrrrr}
\hline & Routine & \multicolumn{2}{c}{ CPS } \\
\hline & Number & (\%) & Number & (\%) \\
\hline Family members always included & & & & \\
Mother & 175 & 96.2 & 178 & 98.3 \\
\hline Father & 175 & 96.2 & 178 & 98.3 \\
\hline Siblings & 174 & 95.6 & 178 & 98.3 \\
\hline Grandparents & 150 & 82.9 & 168 & 93.9 \\
\hline Aunts/uncles & 101 & 56.7 & 145 & 80.1 \\
\hline Half siblings & 72 & 41.1 & 89 & 51.1 \\
\hline First cousins & 57 & 32.2 & 122 & 68.2 \\
\hline Great aunts/uncles & 22 & 12.8 & 70 & 39.8 \\
\hline Adopted siblings & 13 & 7.8 & 16 & 9.8 \\
\hline Great grandparents & 25 & 14.6 & 65 & 37.6 \\
\hline Step parents & 7 & 4.2 & 12 & 7.3 \\
\hline Family history review frequency & & & & \\
\hline Never & 1 & 0.5 & 0 & 0 \\
\hline Only if the patient mentions an update & 108 & 58.1 & 67 & 37.0 \\
\hline Most of the time & 40 & 21.5 & 74 & 40.9 \\
\hline Every appointment & 18 & 9.7 & 27 & 14.9 \\
\hline Other & 19 & 10.2 & 13 & 7.2
\end{tabular}

\subsubsection{Barriers to Complete Family History}

Given that family history information may be incomplete, we asked participants how often a list of barriers interfered with obtaining a family history. Overall, respondents felt the patient/parent's lack of knowledge of the family history interfered a lot $(43.2 \%, 79 / 183)$ or a great deal $(16.4 \%, 30 / 183)$ with obtaining a family history. Eighty percent (46/183) felt this was the most challenging aspect. Most respondents disagreed with previously published data and indicated barriers to family history elicitation either interfered a little or not at all. These barriers included patient or parent's anxiety $(70.5 \%, 129 / 183)$, timing of family history elicitation in relation to diagnosis $(53.6 \%, 98 / 183)$, and allocation of the provider's time $(55.2 \%, 101 / 183)$ (Figure 2A). 


\subsubsection{Barriers to Genetics Referrals}

Respondents indicated that hematologists/oncologists are the most appropriate practitioner to refer a child for assessment for a CPS, yet most participants rarely refer for this purpose. To investigate potential barriers to genetics referrals, participants were asked the extent to which each issue was a barrier to referral. Most participants indicated patient knowledge of family history was probably $(59.4 \%, 107 / 180)$ or definitely $(12.8 \%, 23 / 180)$ a barrier (Figure 2B). Other items identified by at least half of respondents to be barriers included priority given other immediate care needs $(63.1 \%, 113 / 180)$, and patient understanding of genetic risk $(52.2 \%, 93 / 178)$.

Lack of available genetics services, and insufficient institutional resources were definitely not barriers for $51.1 \%(92 / 180)$ and $55 \%$ (99/180) of respondents, respectively, contrary to data from other settings. In addition, 41.1\% (74/180) and 30\% (54/180) of participants indicated patient eligibility for genetics services was probably not or definitely not a barrier to referrals for their patients. Other issues including familiarity with genetic conditions, limited time at appointments, cost and/or insurance coverage, and lack of referral guidelines were less likely to be considered barriers.

Priority of the referral compared to other patient needs was determined to be the most challenging barrier for $24 \%$ (44/183) of respondents. Patient knowledge of family history was not only considered a barrier to collection of family history information but also to genetics referral $(21.3 \%, 39 / 183)$, as was cost/insurance coverage $(12 \%, 22 / 183)$. Other issues were acknowledged by less than $10 \%$ of the respondents as the most significant barrier to referral. 

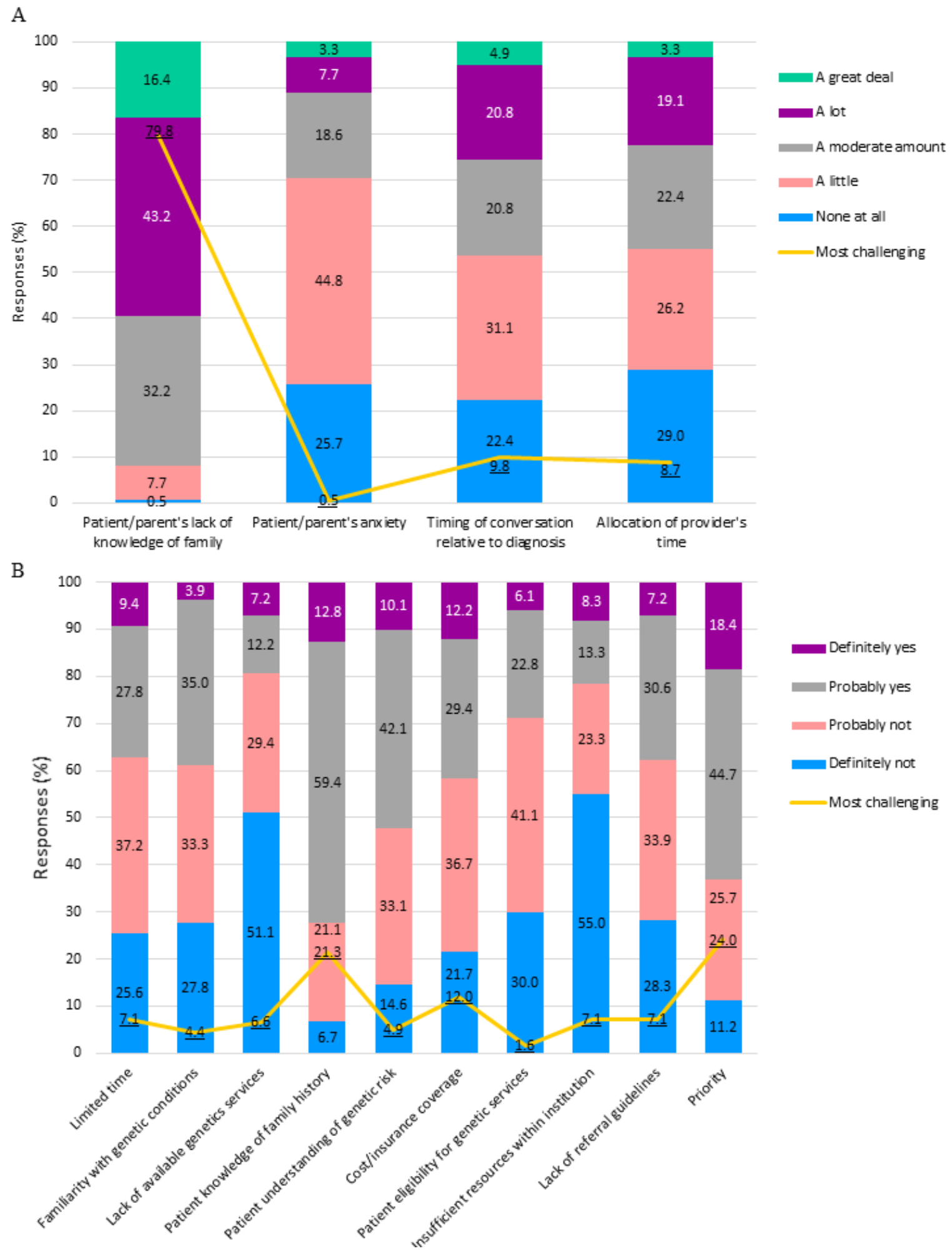

Figure 2. Barriers. A. Barriers perceived by respondents to interfere with obtaining a complete family history. B. Barriers to genetics referral perceived by respondents. 


\subsection{Discussion}

\subsubsection{Current Practices and Perceived Barriers to Referral}

This study assessed current referral practices of pediatric HCP for patients with a suspected CPS. To our knowledge, this is the first national study to investigate self-reported CPS guideline usage, and perceived barriers to pediatric genetics evaluation for CPS. The majority of respondents were attending pediatric hematologists/oncologists located throughout the United States representing a range of years in practice.

Nearly $84 \%$ of respondents indicated that hematologists/oncologists were the most appropriate $\mathrm{HCP}$ to refer a patient with a suspected CPS for genetics evaluation. Of these participants, $72.7 \%$ were hematologists/oncologists themselves, yet close to three quarters of all participants indicated they only sometimes or rarely refer such patients. Recent data suggest the prevalence of CPS in the pediatric cancer population ranges from $7.6-35.5 \% .^{2-9}$ Thus respondents may have indicated they rarely refer patients because they rarely encounter appropriate patients for referral, or because other barriers prevent it. This study was designed to address the latter by investigating referral behaviors and the relationship to respondent demographics.

The majority of respondents indicated they used guidelines to assess patients for referral and more than half were satisfied with the guidelines they use. Guideline use was associated with CPS clinical volume over 5\%. Overall, participants were more likely to refer patients with malignancy and additional features of a CPS than they were for a specific type of cancer. PPGL was the only type of cancer the largest proportion of participants indicated they were likely to always refer for evaluation of a CPS, although guidelines recommend all index cases of PPGL be assessed for a CPS. These guidelines, published by American and European professional societies, 
also recommend referral for cases of CPC, medulloblastoma, and sarcoma regardless of family history yet most respondents indicated they rarely refer patients with such malignancies for genetics evaluation despite their strong association with CPS.${ }^{11,15,17}$ Regardless of guideline usage, these data suggest further education and guidance is required for providers, especially in a rapidly changing field such as genetics. In fact, tumor and germline sequencing in pediatric oncology has already discovered new candidate cancer predisposition genes, which may become relevant to patient care. $^{6,48}$

When it came to features associated with a CPS, likelihood to refer varied by the specific feature, and was generally not associated with guideline use except for immune deficiencies. Overall, respondents were likely to refer patients with malignancy and abnormal growth or excessive toxicity to cancer therapy, however, unfamiliarity with guidelines led to significantly decreased tendency to refer. The features described in this section of the survey were based on criteria described by European groups and thus may not be familiar to our American cohort. ${ }^{11,14}$ Nonetheless, inconsistency to refer for each CPS feature suggests participants may consider additional factors and/or be using different guidelines to assess whether to refer a patient for a suspected CPS.

In addition to guidelines, family history is often utilized to assess for a CPS, however, many factors may contribute to an incomplete family history. ${ }^{24,28,53,59-61}$ In this study, the most challenging aspect of obtaining a family history identified by participants was the patient/parent's lack of knowledge about the family. Respondents also indicated that patient/parent's lack of family history knowledge was the most challenging barrier to genetics referral. Together these data suggest both physician and patient factors contribute to incomplete family history documentation and suggest respondents rely on complete, positive family histories to elicit referral. ${ }^{18}$ The 
American Society of Clinical Oncology (ASCO) has released a statement to define the minimum family history information required for assessment and to provide guidance on interpretation. ${ }^{81}$ Nonetheless, survey respondents reported they do not always collect a full three-generation pedigree, the gold standard in genetics, or a two-generation pedigree as recommended by ASCO, which is concordant with data from other studies. ${ }^{22,27,81}$ Patient knowledge may limit family history elicitation, but should not prevent referral of patients with high-risk tumors for evaluation.

Patient needs are prioritized during oncology visits and family history elicitation may initially be deferred, but research in the pediatric cancer survivor setting has illustrated the importance of frequent family history review. ${ }^{1,42,44}$ As expected, respondents indicated they reviewed family history more often for patients with a suspected CPS, yet only $14.9 \%$ reviewed family history at every appointment. Instead, the most common answers were most of the time or if the patient mentioned an update. Some respondents may see their patients more often than the family history would be expected to change thus decreasing the proportion of physicians who would review history at every appointment, however, patients are less likely to mention updates unprompted and thus these responses may represent missed referral opportunities. ${ }^{24}$

In addition to family history review, cancer predisposition evaluation may be considered low priority given other patient needs. ${ }^{1,15}$ Nearly two thirds of respondents indicated priority was a barrier to genetics referral and it was considered the most significant barrier by $24 \%$. Indeed, the majority of participants surveyed were hematologists/oncologists and pediatric surgeons whose main concerns are focused on the acute needs of their patients. Of note, limited time was not identified as a barrier by most respondents. Evidence suggests that HCP who deem genetics integral to their practice are more likely to refer. ${ }^{65}$ While referral to another specialist at an overwhelming and busy time for the family may not take top priority for the treating physician, 
identification of a CPS can have immediate effects on the patient's siblings, parents, and other family members and should be addressed in a timely manner. ${ }^{1}$ Patients with an underlying CPS have been identified by family history review in survivorship clinics which may be an option for family history review for some practitioners. ${ }^{42,44}$ Alternatively, family history could be elicited by a genetic counselor shortly after diagnosis, or collected briefly by the oncologist at diagnosis and reviewed by a genetic counselor following completion of therapy. This would ensure immediate care needs were met and that the patient was appropriately assessed before discharge.

This survey focused on barriers to physician-initiated referrals. Interestingly, patient understanding of genetic risk, a patient-centered issue, was considered a barrier by over half of respondents. This issue is often considered in the context of referral uptake rather than the initiation of the referral itself. ${ }^{82}$ Other groups have addressed this problem successfully by embedding genetic counseling services into adult oncology clinics. ${ }^{72,73}$ Further information is required to understand why physicians considered this a barrier to referral, though there is evidence from primary care research that indicates physicians with less confidence in their own ability to explain genetics concepts to their patients are less likely to refer to a genetics professional. ${ }^{25}$

Contrary to other studies, access to genetics services, professionals, and resources generally and within the respondent's institution were not perceived as barriers to referral. ${ }^{19,25,30,64}$ In fact, almost $60 \%$ of participants reported their institution has a cancer predisposition clinic and most participants receive helpful feedback on referrals. While most participants also indicated access to a genetic counselor, geneticist, or other colleague with expertise in CPS for formal or informal consultations, further implementation of genetics into the pediatric oncology clinic may be beneficial to the identification of patients with an underlying CPS, especially since over a quarter of respondents do not receive feedback following referral. ${ }^{83}$ While nearly half of 
respondents indicated they participate in molecular/genetics tumor boards, $31.9 \%$ of respondents indicated their institution conducts tumor boards but they do not attend. This may represent an opportunity for genetic counselors and others with expertise in CPS to educate colleagues and increase referrals, and participation from multiple departments should be encouraged. This may also ensure consistent referral practices within an institution, as our data suggests only $16 \%$ of respondents follow institutional referral guidelines.

Over half of respondents surveyed indicated cost/insurance coverage and patient eligibility for genetic services were not barriers to genetics referrals, however cost/insurance coverage was identified as the most challenging barrier to referral by $12 \%$ of respondents. This suggests it is a significant issue to a small number of providers. The severity of these issues may depend on regional insurance coverage. Data collected for this study are not large enough to make conclusions on this matter, however, these are commonly reported barriers to genetics referral in other practice settings as well. ${ }^{30-32,64,67}$ Nonetheless, it is encouraging that cost/insurance coverage and patient eligibility are not major barriers to referral for CPS evaluation for these participants.

Although most participants surveyed use referral guidelines, almost half of those who do not indicated a lack of guideline availability or unawareness of guidelines as the reason. One respondent commented that guidelines would be more useful if risk for a CPS was defined relative to family history, whereas others indicated their institutions refer all pediatric oncology patients. These comments demonstrate a lack of consensus on which patients should be referred for CPS evaluation and how strictly guidelines are followed by the pediatric oncology community. This is a problem others have documented. ${ }^{52,84}$ While it may not be feasible for each cancer predisposition clinic to accept referrals of all pediatric oncology patients, guidelines aim to ensure a balance between the benefit of diagnosing children with an underlying CPS and the risks of over-referring 
patients to genetics/cancer predisposition clinics. This must also be balanced with the availability of genetics professionals to prevent overwhelming the genetics workforce, of which there is a documented shortage. ${ }^{85,86}$ Therefore, efforts should be made to develop and distribute sensitive, specific, easy-to-use guidelines for CPS evaluation and to encourage consultation between specialties to increase appropriate referrals.

Evidence suggests lack of adherence to guidelines is closely related to genetics knowledge and perceived clinical utility. ${ }^{57,69}$ The majority of respondents reported they received adequate genetics education during their training (Appendix A, Table 2) and stated scientific literature, personal communications with genetics professionals, and multidisciplinary tumor board meetings as the major channels through which they continue to obtain information. Over half of respondents also indicated familiarity with genetic conditions was not a barrier to genetics referral. This study was not designed to measure genetics knowledge, but it does suggest that further education may be helpful to aid survey respondents in identification of patients who may benefit from genetics evaluation for a CPS.

Gaps in genetics knowledge, family history elicitation, logistical details, and referral recommendations may prevent or delay referrals for CPS evaluation. Genetics professionals including geneticists, genetic counselors, and/or other HCP with expertise in CPS are specially trained to address these issues. While our data suggest many pediatric oncology providers surveyed consult their genetics colleagues, there is room to improve. Genetic counselors may offer a valuable set of skills to address both physician and patient-centered barriers, and utilization of their skills has proven beneficial in similar settings ${ }^{72,73}$ However, a recent survey of pediatric HCP in a multi-disciplinary hematology/oncology clinic found that providers perceive many genetic 
counselor roles as shared and suggests the role of genetic counselors within a multi-disciplinary team may require clarification of expectations to prioritize their time and effort. ${ }^{87}$

\subsubsection{Limitations}

Limitations to this study include the low response rate which may have been due to the short data collection phase, and availability of respondents. Participants were not asked to specify which guidelines they use, preventing further association of responses with specific guideline recommendations. Referral behavior questions addressed likelihood or frequency of referral and wording was not consistent between these questions which may have changed respondents' interpretations. For instance, participants were asked how often they refer patients with specific cancer types. This may have been interpreted as how often they encounter and refer such patients rather than how often they refer a patient given that specific malignancy. This survey focused on behaviors and attitudes and did not quantify referral rates. Although the survey was piloted, it was not formally validated with content validity or reliability measures. ${ }^{88}$

\subsubsection{Future Directions}

The majority of survey respondents reported the use of referral guidelines to aid in their decision making, yet guideline use was not significantly correlated with referral frequency for a number of factors in this study. Additional research is required to elucidate which specific guidelines pediatric oncology HCP use, and how closely they are followed. Efforts may be focused on enhanced distribution of guidelines as some participants were unaware of guidelines for referral of patients with a suspected CPS. 
Future studies may quantify pediatric oncology healthcare provider's knowledge about CPS to elucidate the relationship between CPS knowledge and guideline adherence, or genetics referral. Lastly, survey respondents represent a small proportion of all pediatric oncology HCP; future work will aim to collect data from a more representative sample of hematology/oncology practitioners and other pediatric providers to understand the perspectives of the care team as a whole.

\subsection{Conclusion}

The use of NGS in pediatric cancer has demonstrated cancer predisposition syndromes have a broader phenotypic spectrum than previously understood. Identification of individuals with an underlying CPS is important for proper management and surveillance of the individual as well as for their family. This is especially important from a public health perspective, as cancer surveillance and disease management differ for patients with a CPS, and early detection of secondary malignancies may be missed by standard treatment-based surveillance protocols.

This study indicates hematologists/oncologists believe they are the most appropriate providers to refer patients in whom a CPS is suspected, yet most rarely refer patients for CPS evaluation. Respondents demonstrated lack of consensus on which patients should be referred for genetic evaluation of a CPS suggesting further education, and clearer guidelines are required to identify this population of patients. We encourage the implementation of genetic counselors or other genetics specialists within pediatric oncology clinics to help address these barriers. Genetic counselors are a valuable resource, specially trained to elicit family histories, assess patient/family risk, and address the unique psychosocial aspects of genetics in the context of pediatric cancer 
care. Furthermore, genetic counselors are knowledgeable about emerging genetic research and advances in the field, making them well suited to disseminate this information and educate their pediatric oncology colleagues.

The results of this study are comparable to findings in adult oncology, but this is the first study the authors are aware of in pediatric oncology that investigates these issues. Overall, these data demonstrate physician, patient, and system level barriers to genetics evaluation for children with a suspected CPS. Both patient and physician factors prevent the collection of in-depth family history information but this should not preclude referral. Education about features and high-risk cancers associated with CPS, more widely distributed referral recommendations, and further implementation of genetics experts into pediatric oncology practices may contribute to increased genetics referrals and ultimately improve recognition of at-risk patients. 


\subsection{Genetic Counseling and Public Health Significance}

This survey aimed to evaluate barriers to genetics referrals for patients with a suspected CPS, which fits with one of the ten essential public health services described by the Centers for Disease Control and Prevention to "evaluate effectiveness, accessibility, and quality of personal and population-based health services" ${ }^{89}$ By evaluating how patients are currently referred, we have identified barriers and have offered recommendations on how appropriate referrals could be increased.

The identification of patients who may have an underlying CPS addresses other essential public health services such as i) monitoring health status, ii) diagnosing health problems in the community, iii) informing, educating and, empowering people about health issues, and iv) linking people to needed personal health services. ${ }^{89}$ Such referrals aid in monitoring health status by identifying and diagnosing patients at increased risk to develop cancer. This extends to the larger community since CPS are often hereditary and the diagnosis of one child has implications for the rest of their family. Furthermore, diagnosis of patients with a CPS may result in management changes and preventative measures which have been shown to be cost effective, and to improve patient outcomes. ${ }^{13,36,90}$

The act of referring at-risk patients to a genetics professional has the potential to inform, educate, and empower patients and their families with information about a CPS. These referrals often involve genetic counselors who are trained to educate, empathize, and facilitate informed decision making for their patients. ${ }^{91}$ Thus, genetic counselors not only help address some of the gaps in knowledge that the referring provider may have, but they possess additional valuable skills 
to aid in patient education and empowerment. Referrals themselves also link patients to $\mathrm{HCP}$ fulfilling another essential public health service.

In summary, this study identified barriers to genetics referrals for a specific population of patients who may have an underlying CPS. These issues are not only barriers to individual patients, but to their families as well. Multidisciplinary teams and cooperation between specialties has the opportunity to benefit patient care. Genetic counselors have expertise in family history assessment, knowledge about CPS, and skills required to address the psychosocial aspects of caring for this population which makes them an integral part of this team. Furthermore, by sharing responsibilities such as family history elicitation and assessment, or educating colleagues about CPS, genetic counselors allow other HCP to focus on different issues.

This study found that pediatric oncology healthcare providers use different criteria to determine whether to refer patients for evaluation of a CPS. Factors influencing the decision to refer include provider knowledge about CPS, priority given the patient's immediate care needs, family history, and patient understanding of genetic risk. Following the identification of these barriers, we recommend the adoption of referral guidelines and further implementation and utilization of genetic counselors trained to address many of the barriers mentioned above. Interventions such as those described above may increase appropriate referrals for patients with a CPS, ultimately improving patient and family outcomes. 


\section{Appendix A Supplemental Figures}

Appendix Table 1. Family history importance.

\begin{tabular}{lrrrr}
\hline & Routine & CPS \\
\hline & Number & (\%) & Number & (\%) \\
\hline Family history is essential to assessment for all new pediatric & & & & \\
oncology patients/patients with a suspected CPS & & & & \\
$\quad$ Strongly agree & 171 & 91.4 & 176 & 94.6 \\
$\quad$ Somewhat agree & 15 & 8.0 & 9 & 4.8 \\
$\quad$ Neither agree nor disagree & 0 & 0.0 & 0 & 0.0 \\
Somewhat disagree & 0 & 0.0 & 1 & 0.5 \\
\hline Strongly disagree & 1 & 0.5 & 0 & 0.0
\end{tabular}

Appendix Table 2. Genetics education.

\begin{tabular}{lrr}
\hline & Number & (\%) \\
\hline $\begin{array}{l}\text { Do you feel you received adequate education in } \\
\text { genetics during your professional training? }\end{array}$ & & \\
$\quad$ Definitely yes & 33 & 17.7 \\
Probably yes & 79 & 42.5 \\
\hline Uncertain & 18 & 9.7 \\
\hline Probably not & 46 & 24.7 \\
\hline Definitely not & 10 & 5.4 \\
\hline
\end{tabular}


Appendix Table 3. Genetic testing.

\begin{tabular}{|c|c|c|}
\hline & Count & $\%$ \\
\hline \multicolumn{3}{|c|}{$\begin{array}{l}\text { Have you ordered genetic testing for patients with a } \\
\text { suspected CPS? }\end{array}$} \\
\hline Never & 23 & 12.4 \\
\hline Rarely (a few times per year) & 89 & 47.8 \\
\hline Sometimes (once per month) & 44 & 23.7 \\
\hline Often (several times per month) & 26 & 14.0 \\
\hline Frequently (several times per week) & 4 & 2.2 \\
\hline \multicolumn{3}{|c|}{$\begin{array}{l}\text { How comfortable are you interpreting somatic genetic } \\
\text { test results for patients with a suspected CPS? }\end{array}$} \\
\hline Extremely uncomfortable & 17 & 9.2 \\
\hline Somewhat uncomfortable & 46 & 25.0 \\
\hline Neither comfortable nor uncomfortable & 34 & 18.5 \\
\hline Somewhat comfortable & 59 & 32.1 \\
\hline Extremely comfortable & 28 & 15.2 \\
\hline \multicolumn{3}{|c|}{$\begin{array}{l}\text { How comfortable are you interpreting germline } \\
\text { genetic test results for patients with a suspected CPS? }\end{array}$} \\
\hline Extremely uncomfortable & 16 & 8.6 \\
\hline Somewhat uncomfortable & 52 & 28.0 \\
\hline Neither comfortable nor uncomfortable & 31 & 16.7 \\
\hline Somewhat comfortable & 66 & 35.5 \\
\hline Extremely comfortable & 22 & 11.8 \\
\hline \multicolumn{3}{|c|}{$\begin{array}{l}\text { Who routinely interprets genetic testing results in } \\
\text { your clinic? Select all that apply }\end{array}$} \\
\hline I do & 85 & 45.9 \\
\hline Medical geneticist & 94 & 50.8 \\
\hline Advanced practice provider & 5 & 2.7 \\
\hline Pathologist & 37 & 20.0 \\
\hline Genetic counselor & 95 & 51.4 \\
\hline Team approach & 77 & 41.6 \\
\hline Other (please specify) & 7 & 3.8 \\
\hline
\end{tabular}


Appendix Table 4. Family history elicitation of new pediatric oncology referral.

\begin{tabular}{|c|c|c|c|c|c|c|c|c|c|c|c|}
\hline & \multicolumn{2}{|c|}{ Never } & \multicolumn{2}{|c|}{ Sometimes } & \multicolumn{2}{|c|}{$\begin{array}{l}\text { About half } \\
\text { the time }\end{array}$} & \multicolumn{2}{|c|}{$\begin{array}{c}\text { Most of the } \\
\text { time }\end{array}$} & \multicolumn{2}{|c|}{ Always } & \multirow[t]{2}{*}{ Total } \\
\hline & Count & $\%$ & Count & $\%$ & Count & $\%$ & Count & $\%$ & Count & $\%$ & \\
\hline Mother & 0 & 0 & 0 & 0 & 0 & 0 & 7 & 3.8 & 175 & 96.2 & 182 \\
\hline Father & 0 & 0 & 0 & 0 & 1 & 0.5 & 6 & 3.3 & 175 & 96.2 & 182 \\
\hline Siblings & 0 & 0 & 0 & 0 & 1 & 0.5 & 7 & 3.8 & 174 & 95.6 & 182 \\
\hline Grandparents & 0 & 0 & 5 & 2.8 & 4 & 2.2 & 22 & 12.2 & 150 & 82.9 & 181 \\
\hline Aunts/uncles & 2 & 1.1 & 17 & 9.6 & 14 & 7.9 & 44 & 24.7 & 101 & 56.7 & 178 \\
\hline First cousins & 9 & 5.1 & 45 & 25.4 & 17 & 9.6 & 49 & 27.7 & 57 & 32.2 & 177 \\
\hline Great aunts/uncles & 31 & 18.0 & 70 & 40.7 & 19 & 11.0 & 30 & 17.4 & 22 & 12.8 & 172 \\
\hline Adopted siblings & 103 & 62.0 & 33 & 19.9 & 6 & 3.6 & 11 & 6.6 & 13 & 7.8 & 166 \\
\hline Half siblings & 22 & 12.6 & 38 & 21.7 & 14 & 8.0 & 29 & 16.6 & 72 & 41.1 & 175 \\
\hline Great grandparents & 34 & 19.9 & 69 & 40.4 & 17 & 9.9 & 26 & 15.2 & 25 & 14.6 & 171 \\
\hline Step parents & 102 & 61.8 & 36 & 21.8 & 6 & 3.6 & 14 & 8.5 & 7 & 4.2 & 165 \\
\hline
\end{tabular}

Appendix Table 5. Family history elicitation of new pediatric oncology referral with a suspected CPS.

\begin{tabular}{|c|c|c|c|c|c|c|c|c|c|c|c|}
\hline & \multicolumn{2}{|c|}{ Never } & \multicolumn{2}{|c|}{ Sometimes } & \multicolumn{2}{|c|}{$\begin{array}{l}\text { About half } \\
\text { the time }\end{array}$} & \multicolumn{2}{|c|}{$\begin{array}{c}\text { Most of the } \\
\text { time }\end{array}$} & \multicolumn{2}{|c|}{ Always } & \multirow[t]{2}{*}{ Total } \\
\hline & Count & $\%$ & Count & $\%$ & Count & $\%$ & Count & $\%$ & Count & $\%$ & \\
\hline Mother & 0 & 0 & 0 & 0 & 0 & 0 & 3 & 1.7 & 178 & 98.3 & 181 \\
\hline Father & 0 & 0 & 0 & 0 & 0 & 0 & 3 & 1.7 & 178 & 98.3 & 181 \\
\hline Siblings & 0 & 0 & 0 & 0 & 0 & 0 & 3 & 1.7 & 178 & 98.3 & 181 \\
\hline Grandparents & 0 & 0 & 0 & 0 & 0 & 0 & 11 & 6.1 & 168 & 93.9 & 179 \\
\hline Aunts/uncles & 1 & 0.6 & 2 & 1.1 & 7 & 3.9 & 26 & 14.4 & 145 & 80.1 & 181 \\
\hline First cousins & 2 & 1.1 & 13 & 7.3 & 13 & 7.3 & 29 & 16.2 & 122 & 68.2 & 179 \\
\hline Great aunts/uncles & 10 & 5.7 & 44 & 25.0 & 19 & 10.8 & 33 & 18.8 & 70 & 39.8 & 176 \\
\hline Adopted siblings & 99 & 60.4 & 32 & 19.5 & 7 & 4.3 & 10 & 6.1 & 16 & 9.8 & 164 \\
\hline Half siblings & 18 & 10.3 & 27 & 15.5 & 16 & 9.2 & 24 & 13.8 & 89 & 51.1 & 174 \\
\hline Great grandparents & 14 & 8.1 & 45 & 26.0 & 15 & 8.7 & 34 & 19.7 & 65 & 37.6 & 173 \\
\hline Step parents & 100 & 61.0 & 34 & 20.7 & 5 & 3.0 & 13 & 7.9 & 12 & 7.3 & 164 \\
\hline
\end{tabular}




\section{Appendix B IRB Approval Letter}

\section{University of Pittsburgh Institutional Review Board}

Human Research Protection Office 3500 Fifth Avenue, Suite 106

Pittsburgh, PA 15213

Tel (412) 383-1480

www.hrpo.pitt.edu

\section{APPROVAL OF SUBMISSION (Exempt)}

\begin{tabular}{|l|l|}
\hline Date: & November 27, 2019 \\
\hline IRB: & STUDY19090002 \\
\hline PI: & Rosemarie Venier \\
\hline Title: & Evaluation of Barriers to Genetics Referral in Pediatric Oncology Clinics \\
\hline
\end{tabular}

The Institutional Review Board reviewed and approved the above referenced study. The study may begin as outlined in the University of Pittsburgh approved application and documents.

Approval Documentation

\begin{tabular}{|l|l|}
\hline Review type: & Initial Study \\
\hline Approval Date: & $11 / 27 / 2019$ \\
\hline Exempt Category: & (2)(ii) Tests, surveys, interviews, or observation (low risk) \\
\hline
\end{tabular}

\begin{tabular}{|l|l|}
\hline Determinations: & - Students / Employees \\
\hline $\begin{array}{l}\text { Approved } \\
\text { Documents: }\end{array}$ & $\begin{array}{l}\text { - Provider Survey_Barriers to Genetics Referral, Category: Data Collection; } \\
\text { - Recruitment Email_Barriers to Genetics Referral, Category: Recruitment } \\
\text { Materials; } \\
\text { - Study 19090002_HRP-711- Tests Surveys Interviews Observations Exemption } \\
1.9 .2019 . \text { docx, Category: IRB Protocol; }\end{array}$ \\
\hline
\end{tabular}

As the Principal Investigator, you are responsible for the conduct of the research and to ensure accurate documentation, protocol compliance, reporting of possibly study-related adverse events and unanticipated problems involving risk to participants or others. The HRPO Reportable Events policy, Chapter 17, is available at http://www.hrpo.pitt.edu/.

Clinical research being conducted in an UPMC facility cannot begin until fiscal approval is received from the UPMC Office of Sponsored Programs and Research Support (OSPARS).

If you have any questions, please contact the University of Pittsburgh IRB Coordinator, Deane Quillen.

Please take a moment to complete our Satisfaction Survey as we appreciate your feedback.

Pitt_510_Exempt 


\section{Appendix C Recruitment Email}

\section{Dear Healthcare Provider,}

My name is Rosemarie Venier. I am currently pursuing a graduate degree in genetic counseling at the University of Pittsburgh. This email serves as an invitation to participate in an online survey to assess the barriers to genetics referrals for pediatric oncology patients with a suspected cancer predisposition syndrome (CPS).

Identification of individuals with a CPS is critical to inform appropriate management and surveillance, yet it is predicted that these individuals are underdiagnosed. Furthermore, there are limited published data on barriers to genetics services in pediatric care. We are interested in the pediatric healthcare provider's role in referral of patients with a suspected CPS to genetics services. We aim to elucidate these details by assessing genetics knowledge, accessibility to genetics services and genetic testing practices of pediatric healthcare providers.

Eligible participants are healthcare providers involved in the care of pediatric oncology patients. Pediatric is defined as birth to age 26 years. You must be currently located in the United States of America to complete the survey. The survey will take approximately 10 minutes to complete. Periodic reminder emails will be sent to encourage survey completion. No direct benefits apply to participants, however, information obtained may inform future practice. No personal contact data will be associated with survey responses. Risks include the possibility of a confidentiality breach of names and email addresses. This risk is reduced by storing information on a secure University of Pittsburgh Medical Center server.

By completing the survey at the link below, you agree to participate in this research study. Participation is voluntary. You may stop the survey at any point and return to complete it using 
the appropriate link below. Incomplete survey responses will be recorded after 2 weeks of inactivity. All response data will be anonymous. Survey data without identifiers may be shared with individuals outside the study team. This survey has been approved by the Institutional Review Board at the University of Pittsburgh. Additional questions can be addressed to the principal investigator, Rosemarie Venier at rev24@pitt.edu. The deadline to complete this survey is [deadline].

Please use this personal link to access the survey. [personal link]

I encourage you to share this email with eligible colleagues, who should use the following link to access the survey. [anonymous link]

Sincerely,

Rosemarie Venier, MSc

MS Genetic Counseling Candidate

University of Pittsburgh 


\section{Appendix D Survey}

\section{Start of Block: Demographics}

Are you currently located in the United States of America?

Yes

No 
What is your level of training? Select all that apply.

MD (staff physician)

MD (fellow/resident)

$\mathrm{PhD}$

Advanced practice provider (PA, NP)

Nurse

Genetic counselor

Other (please specify) 
What is your specialty?

Hematology/oncology

Genetics

Pediatrics

Pathology

Other (please specify)

Do you feel you received adequate education in genetics during your professional training?

Definitely yes

Probably yes

Uncertain

Probably not

Definitely not 
What sources do you obtain information about genetics from? Select all that apply.

Scientific literature

Fellowship/training

CME activities

Personal communication with genetics professionals

Multi-disciplinary tumor board meeting

Other (please specify) 
What is your age?

$\leq 30$

30-39

$40-49$

$50-59$

$60-69$

$\geq 70$

How many years have you been practicing?

\section{Currently training}

Less than 5

5-10

$11-20$

$20+$ 
In which state do you see most patients?

AL ... International

What setting do you practice in? Select all that apply.

Children's hospital within an academic/university center (not freestanding)

Freestanding children's hospital

Private practice

Other (please explain) 
What is your clinical volume of new pediatric oncology patients per year?

Less than 100

$100-250$

More than 250

Not currently seeing patients

What percentage of your patients have a diagnosed cancer predisposition syndrome (CPS)? (Ex. Li-Fraumeni syndrome, Beckwith-Wiedemann syndrome, Cowden syndrome)
None
Less than $5 \%$
$5-10 \%$
More than $10 \%$ (please explain)
Unsure 
Do you have access to a genetics specialist (geneticist, genetic counselor)?

Yes

No

Unsure

What type of genetics specialist do you have access to? Select all that apply.

Geneticist

Certified genetic counselor

Other (please specify) 
Family history is essential to the assessment of all new pediatric oncology patients.

Strongly agree

Somewhat agree

Neither agree nor disagree

Somewhat disagree

Strongly disagree 
Family history is essential to the assessment of suspected cancer predisposition syndrome patients.

Strongly agree

Somewhat agree

Neither agree nor disagree

Somewhat disagree

Strongly disagree

Following an initial appointment for a new pediatric oncology referral, how often do you review family history (ex. asking if there have been new diagnoses in the family)?

Never

Only if the patient mentions an update

Most of the time

Every appointment

Other 
Following an initial appointment for a new pediatric oncology referral with a suspected cancer predisposition syndrome, how often do you review family history (ex. asking if there have been new diagnoses in the family)?

Never

Only if the patient/parent mentions an update

Most of the time

Every appointment

Other 
A new pediatric oncology referral presents to your clinic. When eliciting family cancer history, which specific family members do you inquire about because it is relevant to your assessment?

\begin{tabular}{|c|c|c|c|c|c|}
\hline & Never & Sometimes & $\begin{array}{l}\text { About } \\
\text { half the time }\end{array}$ & $\begin{array}{l}\text { Most } \\
\text { of the time }\end{array}$ & Always \\
\hline \multicolumn{6}{|l|}{ Mother } \\
\hline \multicolumn{6}{|l|}{ Father } \\
\hline \multicolumn{6}{|l|}{ Siblings } \\
\hline \multicolumn{6}{|l|}{ Grandparents } \\
\hline \multicolumn{6}{|l|}{ Aunts/uncles } \\
\hline \multicolumn{6}{|l|}{ First cousins } \\
\hline \multicolumn{6}{|l|}{$\begin{array}{l}\text { Great } \\
\text { aunts/uncles }\end{array}$} \\
\hline \multicolumn{6}{|c|}{ Adopted siblings } \\
\hline \multicolumn{6}{|l|}{ Half siblings } \\
\hline \multicolumn{6}{|l|}{$\begin{array}{l}\text { Great } \\
\text { grandparents }\end{array}$} \\
\hline Step parents & & & & & \\
\hline
\end{tabular}


A new pediatric oncology referral with a suspected cancer predisposition syndrome presents to your clinic. When eliciting family cancer history, which specific family members do you inquire about because it is relevant to your assessment?

\begin{tabular}{|c|c|c|c|c|c|}
\hline & Never & Sometimes & $\begin{array}{l}\text { About } \\
\text { half the time }\end{array}$ & $\begin{array}{l}\text { Most } \\
\text { of the time }\end{array}$ & Always \\
\hline \multicolumn{6}{|l|}{ Mother } \\
\hline \multicolumn{6}{|l|}{ Father } \\
\hline \multicolumn{6}{|l|}{ Siblings } \\
\hline \multicolumn{6}{|l|}{ Grandparents } \\
\hline \multicolumn{6}{|l|}{ Aunts/uncles } \\
\hline \multicolumn{6}{|l|}{ First cousins } \\
\hline \multicolumn{6}{|l|}{$\begin{array}{l}\text { Great } \\
\text { aunts/uncles }\end{array}$} \\
\hline \multicolumn{6}{|c|}{ Adopted siblings } \\
\hline \multicolumn{6}{|l|}{ Half siblings } \\
\hline \multicolumn{6}{|l|}{$\begin{array}{l}\text { Great } \\
\text { grandparents }\end{array}$} \\
\hline Step parents & & & & & \\
\hline
\end{tabular}


How often do the following interfere with obtaining a family history?

\begin{tabular}{l|l|l} 
& None at all A little & $\begin{array}{c}\text { A moderate } \\
\text { amount }\end{array}$ \\
\hline $\begin{array}{l}\text { Patient/parent's lack } \\
\text { of knowledge of family }\end{array}$ \\
Patient/parent's \\
anxiety \\
Timing of conversation \\
relative to diagnosis \\
Allocation of provider's \\
time
\end{tabular}

What is the most challenging aspect of obtaining a family history?

Patient/parent's lack of knowledge of family

Patient/parent's anxiety

Timing of conversation relative to diagnosis

Allocation of provider's time

Other (please specify) 
End of Block: Family History

Start of Block: Barriers 
To what extent are the following items barriers to genetics referrals in your practice?

\begin{tabular}{|c|c|c|c|c|}
\hline & Definitely not & Probably not & Probably yes & Definitely yes \\
\hline $\begin{array}{l}\text { Limited time at } \\
\text { appointments }\end{array}$ & 0 & 0 & 0 & $\bigcirc$ \\
\hline $\begin{array}{l}\text { Familiarity with } \\
\text { genetic conditions }\end{array}$ & 0 & 0 & 0 & 0 \\
\hline $\begin{array}{l}\text { Lack of available } \\
\text { genetics services }\end{array}$ & $\bigcirc$ & 0 & 0 & $\bigcirc$ \\
\hline $\begin{array}{l}\text { Patient knowledge } \\
\text { of family history }\end{array}$ & 0 & 0 & 0 & 0 \\
\hline $\begin{array}{l}\text { Patient } \\
\text { understanding of } \\
\text { genetic risk }\end{array}$ & 0 & 0 & 0 & 0 \\
\hline $\begin{array}{l}\text { Cost/insurance } \\
\text { coverage }\end{array}$ & 0 & 0 & 0 & 0 \\
\hline $\begin{array}{l}\text { Patient eligibility for } \\
\text { genetic services }\end{array}$ & 0 & 0 & 0 & 0 \\
\hline $\begin{array}{l}\text { Insufficient } \\
\text { resources within } \\
\text { institution (lack of } \\
\text { genetics } \\
\text { professionals) }\end{array}$ & 0 & 0 & 0 & $\bigcirc$ \\
\hline $\begin{array}{l}\text { Lack of referral } \\
\text { guidelines }\end{array}$ & 0 & 0 & 0 & 0 \\
\hline $\begin{array}{l}\text { Priority (given } \\
\text { patient's treatment, } \\
\text { immediate care } \\
\text { needs, etc.) }\end{array}$ & 0 & 0 & 0 & 0 \\
\hline $\begin{array}{l}\text { Other (please } \\
\text { specify) }\end{array}$ & 0 & 0 & 0 & 0 \\
\hline
\end{tabular}


What is the most significant barrier to genetics referral in your practice?

Limited time at appointments

Familiarity with genetic conditions

Lack of available genetics services

Patient knowledge of family history

Patient understanding of genetic risk

Cost/insurance coverage

Patient eligibility for genetic services

Insufficient resources within institution (lack of genetics professionals)

Lack of referral guidelines

Priority (given patient's treatment, immediate care needs, etc.

Other (please specify) 
How often do you refer patients to genetics for a cancer predisposition evaluation?

Never

Rarely (a few times per year)

Sometimes (once per month)

Often (several times per month)

Frequently (several times per week)

N/A

Does your institution have a cancer predisposition clinic?

Yes

$\bigcirc$ No

Unsure 
What department is the cancer predisposition clinic part of?

Hematology/oncology

Medical genetics

Other (please specify)

Do you use formal/published guidelines when deciding whether to refer to genetics? For example, NCCN, ACMG/NSGC (Hampel et al. 2015), Jongmans criteria (Jongmans et al. 2016).

Yes

No

Sometimes 
Do all providers in your clinic use the same referral guidelines?

Yes

No

Unsure

Display This Question:

If Do you use formal/published guidelines when deciding whether to refer to genetics? For example, N... != No

How satisfied are you with the referral guidelines you use?

Extremely satisfied

Somewhat satisfied

Neither satisfied nor dissatisfied

Somewhat dissatisfied

Extremely dissatisfied 
What is the main reason for not using formal referral guidelines?

Lack of available guidelines

Conflicting guidelines from different sources

Feel confident in referring without them

I do use them

Other (please specify)

Do you receive feedback from a genetics clinic regarding your referrals? (Inappropriate/appropriate referrals, suggested guidelines, etc.)

Yes

No

Unsure 
Please explain the nature of feedback from the genetics clinic.

Do you consult a genetics specialist or cancer predisposition oncologist when you suspect a patient has a cancer predisposition syndrome? For the purpose of this question, genetics specialist refers to a clinical or laboratory geneticist or genetic counselor.
Yes
No
Sometimes
N/A

\section{Display This Question:}


Would consulting a genetics specialist or cancer predisposition oncologist be helpful when you suspect a patient has a cancer predisposition syndrome?

Yes

No

Sometimes

Do you participate in institutional molecular/genetics tumor boards?

Yes

No, but there are tumor boards in my institution

No, there are no tumor boards at my institution

\section{End of Block: Genetics Accessibility}

Start of Block: Genetic Testing

$x \rightarrow$ 
Have you ordered genetic testing for patients with a suspected cancer predisposition syndrome?

$\bigcirc$ Never

Rarely (a few times per year)

Sometimes (once per month)

Often (several times per month)

Frequently (several times per week)

How comfortable are you interpreting somatic genetic test results for patients with a suspected cancer predisposition syndrome?

Extremely uncomfortable

Somewhat uncomfortable

Neither comfortable nor uncomfortable

Somewhat comfortable

Extremely comfortable 
How comfortable are you interpreting germline genetic test results for patients with a suspected cancer predisposition syndrome?

Extremely uncomfortable

Somewhat uncomfortable

Neither comfortable nor uncomfortable

Somewhat comfortable

Extremely comfortable 
Who routinely interprets genetic testing results in your clinic? Select all that apply.

I do

Medical geneticist

Advanced practice provider

Pathologist

Genetic counselor

Team approach

Other (please specify) 
How are positive genetic test results (pathogenic mutation detected) routinely delivered to the patients in your clinic? Select all that apply.

In person

On the phone

Voicemail

$\square$ Letter

Other (please specify)

\section{End of Block: Genetic Testing}

Start of Block: Knowledge 
A patient presents to your clinic with malignancy. How likely are you to consider a cancer predisposition syndrome if they also present with the following? 


\begin{tabular}{|c|c|c|c|c|c|}
\hline & $\begin{array}{l}\text { Extremely } \\
\text { unlikely }\end{array}$ & $\begin{array}{l}\text { Somewhat } \\
\text { unlikely }\end{array}$ & $\begin{array}{l}\text { Neither likely } \\
\text { nor unlikely }\end{array}$ & $\begin{array}{l}\text { Somewhat } \\
\text { likely }\end{array}$ & Extremely likely \\
\hline $\begin{array}{l}\text { Genetic results } \\
\text { from tumor that } \\
\text { indicate somatic } \\
\text { mutation in a } \\
\text { predisposition } \\
\text { gene (ex. TP53, } \\
\text { PTEN) }\end{array}$ & & & & & \\
\hline $\begin{array}{l}\text { Genetic results } \\
\text { from tumor that } \\
\text { suggest a } \\
\text { germline } \\
\text { mutation in a } \\
\text { predisposition } \\
\text { gene (ex. TP53, } \\
\text { PTEN) }\end{array}$ & & & & & \\
\hline $\begin{array}{l}\text { Congenital } \\
\text { anomalies }\end{array}$ & & & & & \\
\hline $\begin{array}{l}\text { Dysmorphic } \\
\text { features }\end{array}$ & & & & & \\
\hline $\begin{array}{l}\text { Developmental } \\
\text { delay/intellectual } \\
\text { disability }\end{array}$ & & & & & \\
\hline $\begin{array}{l}\text { Abnormal } \\
\text { growth (head } \\
\text { circumference, } \\
\text { birth weight, } \\
\text { height, } \\
\text { hemihyperplasia) }\end{array}$ & & & & & \\
\hline $\begin{array}{l}\text { Environmental } \\
\text { exposure }\end{array}$ & & & & & \\
\hline $\begin{array}{l}\text { Skin } \\
\text { abnormalities } \\
\text { (pigmentation, } \\
\text { hypersensitivity } \\
\text { to sun, vascular } \\
\text { lesions) }\end{array}$ & & & & & \\
\hline $\begin{array}{l}\text { Hematological } \\
\text { abnormalities } \\
\text { (not explained by } \\
\text { current } \\
\text { malignancy) }\end{array}$ & & & & & \\
\hline
\end{tabular}




Immune
deficiency
Endocrine
abnormalities
(precocious
puberty,
acromegaly)
Excessive toxicity
to cancer
therapy
Multiple
malignancies
(bilateral,
multifocal,
secondary,
metachronous)


How often do you refer patients with the following diagnosis for a cancer predisposition evaluation?

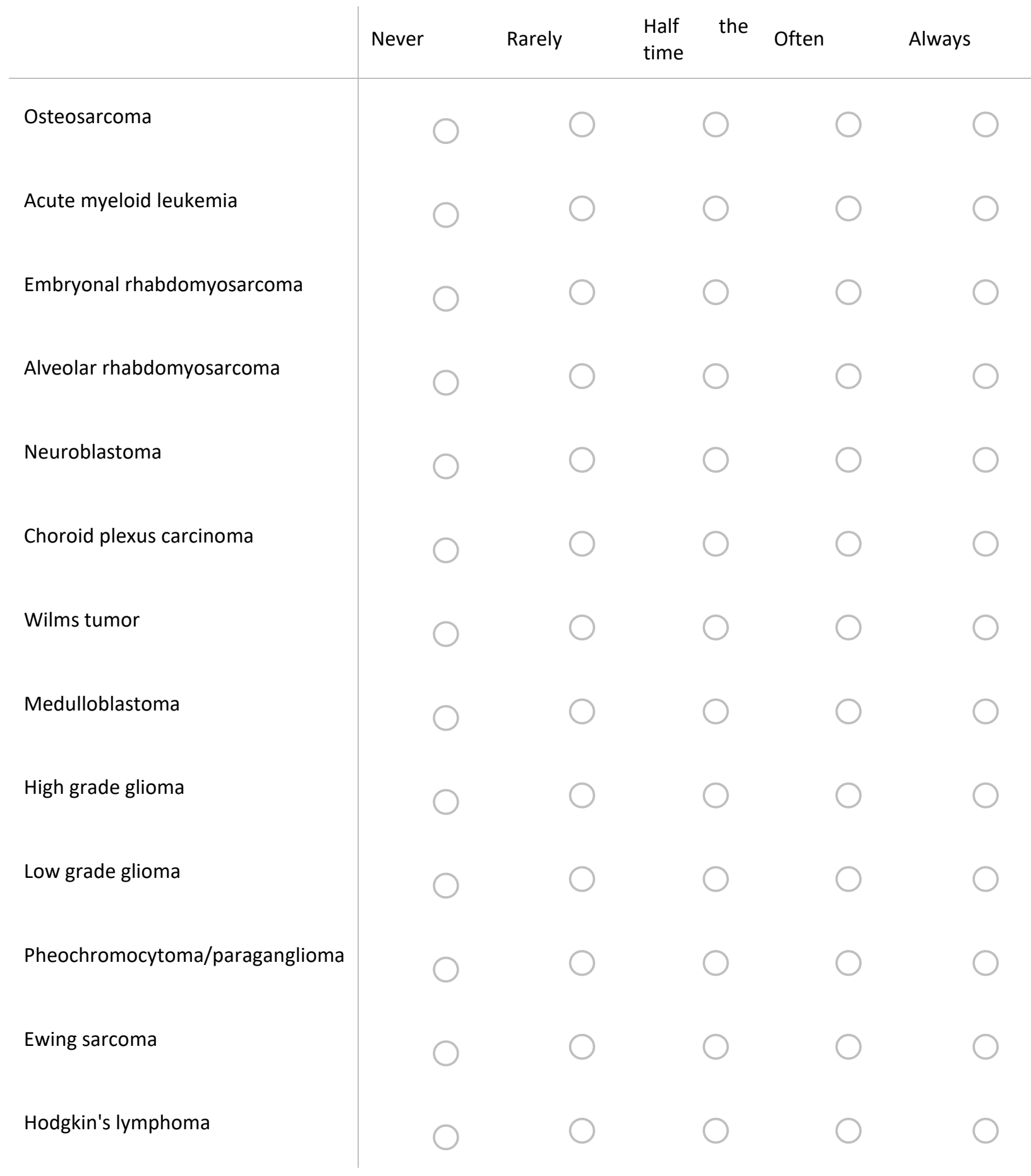


Who is the most appropriate healthcare practitioner to refer a patient with a cancer predisposition syndrome to genetics?

\section{Hematologist/Oncologist}

Medical geneticist

Advanced practice provider

Pathologist

Genetic counselor

Primary care physician

Survivorship clinician

Other (please specify) 
Who is the most appropriate healthcare practitioner to diagnose a patient with a cancer predisposition syndrome?

\section{Hematologist/Oncologist}

Medical geneticist

Advanced practice provider

Pathologist

Genetic counselor

Primary care physician

Survivorship clinician

Other (please specify) 


\section{Bibliography}

1. Schiffman JD. Hereditary cancer syndromes: if you look, you will find them. Pediatr Blood Cancer. 2012;58(1):5-6.

2. Zhang J, Walsh MF, Wu G, et al. Germline Mutations in Predisposition Genes in Pediatric Cancer. N Engl J Med. 2015;373(24):2336-2346.

3. Grobner SN, Worst BC, Weischenfeldt J, et al. The landscape of genomic alterations across childhood cancers. Nature. 2018;555(7696):321-327.

4. Mody RJ, Wu YM, Lonigro RJ, et al. Integrative Clinical Sequencing in the Management of Refractory or Relapsed Cancer in Youth. JAMA. 2015;314(9):913-925.

5. Oberg JA, Glade Bender JL, Sulis ML, et al. Implementation of next generation sequencing into pediatric hematology-oncology practice: moving beyond actionable alterations. Genome Med. 2016;8(1):133.

6. Chang W, Brohl AS, Patidar R, et al. MultiDimensional ClinOmics for Precision Therapy of Children and Adolescent Young Adults with Relapsed and Refractory Cancer: A Report from the Center for Cancer Research. Clin Cancer Res. 2016;22(15):3810-3820.

7. Kline CN, Joseph NM, Grenert JP, et al. Targeted next-generation sequencing of pediatric neuro-oncology patients improves diagnosis, identifies pathogenic germline mutations, and directs targeted therapy. Neuro Oncol. 2017;19(5):699-709.

8. Diets IJ, Waanders E, Ligtenberg MJ, et al. High Yield of Pathogenic Germline Mutations Causative or Likely Causative of the Cancer Phenotype in Selected Children with Cancer. Clin Cancer Res. 2018;24(7):1594-1603.

9. Parsons DW, Roy A, Yang Y, et al. Diagnostic Yield of Clinical Tumor and Germline Whole-Exome Sequencing for Children With Solid Tumors. JAMA Oncol. 2016;2(5):616624.

10. Garber JE, Offit K. Hereditary cancer predisposition syndromes. J Clin Oncol. 2005;23(2):276-292.

11. Jongmans MC, Loeffen JL, Waanders E, et al. Recognition of genetic predisposition in pediatric cancer patients: An easy-to-use selection tool. Eur J Med Genet. 2016;59(3):116125.

12. Malkin D, Nichols KE, Schiffman JD, Plon SE, Brodeur GM. The Future of Surveillance in the Context of Cancer Predisposition: Through the Murky Looking Glass. Clin Cancer Res. 2017;23(21):e133-e137.

13. Villani A, Shore A, Wasserman JD, et al. Biochemical and imaging surveillance in germline TP53 mutation carriers with Li-Fraumeni syndrome: 11 year follow-up of a prospective observational study. Lancet Oncol. 2016;17(9):1295-1305.

14. Ripperger T, Bielack SS, Borkhardt A, et al. Childhood cancer predisposition syndromesA concise review and recommendations by the Cancer Predisposition Working Group of the Society for Pediatric Oncology and Hematology. Am $J$ Med Genet A. 2017;173(4):1017-1037.

15. Druker H, Zelley K, McGee RB, et al. Genetic Counselor Recommendations for Cancer Predisposition Evaluation and Surveillance in the Pediatric Oncology Patient. Clin Cancer Res. 2017;23(13):e91-e97. 
16. Smith RA, Andrews KS, Brooks D, et al. Cancer screening in the United States, 2018: A review of current American Cancer Society guidelines and current issues in cancer screening. CA Cancer J Clin. 2018;68(4):297-316.

17. Hampel H, Bennett RL, Buchanan A, et al. A practice guideline from the American College of Medical Genetics and Genomics and the National Society of Genetic Counselors: referral indications for cancer predisposition assessment. Genet Med. 2015;17(1):70-87.

18. Febbraro T, Robison K, Wilbur JS, et al. Adherence patterns to National Comprehensive Cancer Network (NCCN) guidelines for referral to cancer genetic professionals. Gynecol Oncol. 2015;138(1):109-114.

19. Garcia C, Harrison K, Ring KL, Sullivan MW, Rauh LA, Modesitt SC. Genetic counseling referral for ovarian cancer patients: a call to action. Fam Cancer. 2019;18(3):303-309.

20. Hoskins PJ, Gotlieb WH. Missed therapeutic and prevention opportunities in women with BRCA-mutated epithelial ovarian cancer and their families due to low referral rates for genetic counseling and BRCA testing: A review of the literature. CA Cancer J Clin. 2017;67(6):493-506.

21. Meyer LA, Anderson ME, Lacour RA, et al. Evaluating women with ovarian cancer for BRCA1 and BRCA2 mutations: missed opportunities. Obstet Gynecol. 2010;115(5):945952.

22. Wood ME, Kadlubek P, Pham TH, et al. Quality of cancer family history and referral for genetic counseling and testing among oncology practices: a pilot test of quality measures as part of the American Society of Clinical Oncology Quality Oncology Practice Initiative. J Clin Oncol. 2014;32(8):824-829.

23. Mikat-Stevens NA, Larson IA, Tarini BA. Primary-care providers' perceived barriers to integration of genetics services: a systematic review of the literature. Genet Med. 2015;17(3):169-176.

24. Al-Habsi H, Lim JN, Chu CE, Hewison J. Factors influencing the referrals in primary care of asymptomatic patients with a family history of cancer. Genet Med. 2008;10(10):751757.

25. Carroll JC, Cappelli M, Miller F, et al. Genetic services for hereditary breast/ovarian and colorectal cancers - physicians' awareness, use and satisfaction. Community Genet. 2008;11(1):43-51.

26. Trinidad SB, Fryer-Edwards K, Crest A, Kyler P, Lloyd-Puryear MA, Burke W. Educational needs in genetic medicine: primary care perspectives. Community Genet. 2008;11(3):160-165.

27. Tarini BA, Gornick MC, Zikmund-Fisher BJ, Saal HM, Edmondson L, Uhlmann WR. Family History Collection Practices: National Survey of Pediatric Primary Care Providers. Clin Pediatr (Phila). 2018;57(5):537-546.

28. Saul RA, Trotter T, Sease K, Tarini B. Survey of family history taking and genetic testing in pediatric practice. J Community Genet. 2017;8(2):109-115.

29. Mathers J, Greenfield S, Metcalfe A, Cole T, Flanagan S, Wilson S. Family history in primary care: understanding GPs' resistance to clinical genetics--qualitative study. $\mathrm{Br} J$ Gen Pract. 2010;60(574):e221-230.

30. Vig HS, Armstrong J, Egleston BL, et al. Cancer genetic risk assessment and referral patterns in primary care. Genet Test Mol Biomarkers. 2009;13(6):735-741.

31. Acheson LS, Stange KC, Zyzanski S. Clinical genetics issues encountered by family physicians. Genet Med. 2005;7(7):501-508. 
32. Brandt R, Ali Z, Sabel A, McHugh T, Gilman P. Cancer genetics evaluation: barriers to and improvements for referral. Genet Test. 2008;12(1):9-12.

33. Robert-Boire V, Rosca L, Samson Y, Ospina LH, Perreault S. Clinical Presentation and Outcome of Patients With Optic Pathway Glioma. Pediatr Neurol. 2017;75:55-60.

34. Nachman JB, Heerema NA, Sather H, et al. Outcome of treatment in children with hypodiploid acute lymphoblastic leukemia. Blood. 2007;110(4):1112-1115.

35. Holmfeldt L, Wei L, Diaz-Flores E, et al. The genomic landscape of hypodiploid acute lymphoblastic leukemia. Nat Genet. 2013;45(3):242-252.

36. Prete FP, Abdel-Aziz T, Morkane C, Brain C, Kurzawinski TR, Group MENiCUC. Prophylactic thyroidectomy in children with multiple endocrine neoplasia type 2. $\mathrm{Br} J$ Surg. 2018;105(10):1319-1327.

37. Robson ME, Bradbury AR, Arun B, et al. American Society of Clinical Oncology Policy Statement Update: Genetic and Genomic Testing for Cancer Susceptibility. J Clin Oncol. 2015;33(31):3660-3667.

38. Malkin D, Li FP, Strong LC, et al. Germ line p53 mutations in a familial syndrome of breast cancer, sarcomas, and other neoplasms. Science. 1990;250(4985):1233-1238.

39. Li FP, Fraumeni JF, Jr. Soft-tissue sarcomas, breast cancer, and other neoplasms. A familial syndrome? Ann Intern Med. 1969;71(4):747-752.

40. Li FP, Fraumeni JF, Jr., Mulvihill JJ, et al. A cancer family syndrome in twenty-four kindreds. Cancer Res. 1988;48(18):5358-5362.

41. Kratz CP, Achatz MI, Brugieres L, et al. Cancer Screening Recommendations for Individuals with Li-Fraumeni Syndrome. Clin Cancer Res. 2017;23(11):e38-e45.

42. Russo S, Warby M, Tucker KM, Wakefield CE, Cohn RJ. Importance of updating family cancer history in childhood cancer survivors. Fam Cancer. 2017;16(4):605-610.

43. Merks JH, Caron HN, Hennekam RC. High incidence of malformation syndromes in a series of 1,073 children with cancer. Am J Med Genet A. 2005;134A(2):132-143.

44. Knapke S, Nagarajan R, Correll J, Kent D, Burns K. Hereditary cancer risk assessment in a pediatric oncology follow-up clinic. Pediatr Blood Cancer. 2012;58(1):85-89.

45. Green RC, Berg JS, Grody WW, et al. ACMG recommendations for reporting of incidental findings in clinical exome and genome sequencing. Genet Med. 2013;15(7):565-574.

46. Kalia SS, Adelman K, Bale SJ, et al. Recommendations for reporting of secondary findings in clinical exome and genome sequencing, 2016 update (ACMG SF v2.0): a policy statement of the American College of Medical Genetics and Genomics. Genet Med. 2017;19(2):249-255.

47. Evans DG, Baser ME, McGaughran J, Sharif S, Howard E, Moran A. Malignant peripheral nerve sheath tumours in neurofibromatosis 1. J Med Genet. 2002;39(5):311-314.

48. Mirabello L, Zhu B, Koster R, et al. Frequency of Pathogenic Germline Variants in CancerSusceptibility Genes in Patients With Osteosarcoma. JAMA Oncol. 2020.

49. Venier RE, Maurer LM, Kessler EM, et al. A germline BARD1 mutation in a patient with Ewing Sarcoma: Implications for familial testing and counseling. Pediatr Blood Cancer. 2019;66(9):e27824.

50. Brohl AS, Patidar R, Turner CE, et al. Frequent inactivating germline mutations in DNA repair genes in patients with Ewing sarcoma. Genet Med. 2017;19(8):955-958.

51. Cohen SA, Gustafson SL, Marvin ML, et al. Report from the National Society of Genetic Counselors service delivery model task force: a proposal to define models, components, and modes of referral. J Genet Couns. 2012;21(5):645-651. 
52. Houwink EJ, van Luijk SJ, Henneman L, van der Vleuten C, Jan Dinant G, Cornel MC. Genetic educational needs and the role of genetics in primary care: a focus group study with multiple perspectives. BMC Fam Pract. 2011;12:5.

53. Bathurst L, Huang QR. A qualitative study of GPs' views on modern genetics. Aust Fam Physician. 2006;35(6):462-464.

54. Aalfs CM, Smets EM, de Haes HC, Leschot NJ. Referral for genetic counselling during pregnancy: limited alertness and awareness about genetic risk factors among GPs. Fam Pract. 2003;20(2):135-141.

55. Weipert CM, Ryan KA, Everett JN, et al. Physician Experiences and Understanding of Genomic Sequencing in Oncology. J Genet Couns. 2018;27(1):187-196.

56. Bonter K, Desjardins C, Currier N, Pun J, Ashbury FD. Personalised medicine in Canada: a survey of adoption and practice in oncology, cardiology and family medicine. BMJ Open. 2011;1(1):e000110.

57. Grover S, Stoffel EM, Bussone L, Tschoegl E, Syngal S. Physician assessment of family cancer history and referral for genetic evaluation in colorectal cancer patients. Clin Gastroenterol Hepatol. 2004;2(9):813-819.

58. Flynn BS, Wood ME, Ashikaga T, Stockdale A, Dana GS, Naud S. Primary care physicians' use of family history for cancer risk assessment. BMC Fam Pract. 2010;11:45.

59. Rinke ML, Mikat-Stevens N, Saul R, Driscoll A, Healy J, Tarini BA. Genetic services and attitudes in primary care pediatrics. Am J Med Genet A. 2014;164A(2):449-455.

60. Acheson LS, Wiesner GL, Zyzanski SJ, Goodwin MA, Stange KC. Family history-taking in community family practice: implications for genetic screening. Genet Med. 2000;2(3):180-185.

61. Wood ME, Stockdale A, Flynn BS. Interviews with primary care physicians regarding taking and interpreting the cancer family history. Fam Pract. 2008;25(5):334-340.

62. Swanson CL, Kumar A, Maharaj JM, et al. Increasing genetic counseling referral rates through bundled interventions after ovarian cancer diagnosis. Gynecol Oncol. 2018;149(1):121-126.

63. Desrosiers LR, Quinn E, Cramer S, Dobek W. Integrating genetic counseling and testing in the pediatric oncology setting: Parental attitudes and influencing factors. Pediatr Blood Cancer. 2019;66(10):e27907.

64. Chen MJ, Holt CL, Lose EJ, Robin NH. The use by Alabama pediatricians of genetics consultation in the evaluation of developmental delay. Am $J$ Med Genet A. 2008;146A(4):421-425.

65. Diamonstein C, Stevens B, Shahrukh Hashmi S, Refuerzo J, Sullivan C, Hoskovec J. Physicians' Awareness and Utilization of Genetic Services in Texas. J Genet Couns. 2018;27(4):968-977.

66. Wilkes MS, Day FC, Fancher TL, et al. Increasing confidence and changing behaviors in primary care providers engaged in genetic counselling. BMC Med Educ. 2017;17(1):163.

67. Freedman AN, Wideroff L, Olson L, et al. US physicians' attitudes toward genetic testing for cancer susceptibility. Am J Med Genet A. 2003;120A(1):63-71.

68. Goudie C, Coltin H, Witkowski L, Mourad S, Malkin D, Foulkes WD. The McGill Interactive Pediatric OncoGenetic Guidelines: An approach to identifying pediatric oncology patients most likely to benefit from a genetic evaluation. Pediatr Blood Cancer. 2017;64(8). 
69. Batra S, Valdimarsdottir H, McGovern M, Itzkowitz S, Brown K. Awareness of genetic testing for colorectal cancer predisposition among specialists in gastroenterology. Am J Gastroenterol. 2002;97(3):729-733.

70. National Comprehensive Cancer Network. Genetic/Familial High-Risk Assessment: Colorectal (Version

3.2019). https://www.nccn.org/professionals/physician_gls/pdf/genetics_colon.pdf. Published 2019. Accessed January 26, 2020.

71. Vasen HF, Moslein G, Alonso A, et al. Guidelines for the clinical management of familial adenomatous polyposis (FAP). Gut. 2008;57(5):704-713.

72. Senter L, O'Malley DM, Backes FJ, et al. Genetic consultation embedded in a gynecologic oncology clinic improves compliance with guideline-based care. Gynecol Oncol. 2017;147(1):110-114.

73. Kentwell M, Dow E, Antill Y, et al. Mainstreaming cancer genetics: A model integrating germline BRCA testing into routine ovarian cancer clinics. Gynecol Oncol. 2017;145(1):130-136.

74. George A, Riddell D, Seal S, et al. Implementing rapid, robust, cost-effective, patientcentred, routine genetic testing in ovarian cancer patients. Sci Rep. 2016;6:29506.

75. National Comprehensive Cancer Network. Genetic/Familial High-Risk Assessment: Breast, Ovarian, and Pancreatic (Version 1.2020). https://www.nccn.org/professionals/physician_gls/pdf/genetics_bop.pdf. Published 2019. Accessed December 4, 2019.

76. Lancaster JM, Powell CB, Chen LM, Richardson DL, Committee SGOCP. Society of Gynecologic Oncology statement on risk assessment for inherited gynecologic cancer predispositions. Gynecol Oncol. 2015;136(1):3-7.

77. Kieran S, Loescher LJ, Lim KH. The role of financial factors in acceptance of clinical BRCA genetic testing. Genet Test. 2007;11(1):101-110.

78. Steffen LE, Du R, Gammon A, et al. Genetic Testing in a Population-Based Sample of Breast and Ovarian Cancer Survivors from the REACH Randomized Trial: Cost Barriers and Moderators of Counseling Mode. Cancer Epidemiol Biomarkers Prev. 2017;26(12):1772-1780.

79. Wilson CL, Wang Z, Liu Q, et al. Estimated number of adult survivors of childhood cancer in United States with cancer-predisposing germline variants. Pediatr Blood Cancer. 2020;67(2):e28047.

80. Liang MI, Wong DH, Walsh CS, Farias-Eisner R, Cohen JG. Cancer Genetic Counseling and Testing: Perspectives of Epithelial Ovarian Cancer Patients and Gynecologic Oncology Healthcare Providers. J Genet Couns. 2018;27(1):177-186.

81. Lu KH, Wood ME, Daniels M, et al. American Society of Clinical Oncology Expert Statement: collection and use of a cancer family history for oncology providers. J Clin Oncol. 2014;32(8):833-840.

82. Rolnick SJ, Rahm AK, Jackson JM, et al. Barriers in identification and referral to genetic counseling for familial cancer risk: the perspective of genetic service providers. J Genet Couns. 2011;20(3):314-322.

83. Kuhlen M, Wieczorek D, Siebert R, Fruhwald MC. How I approach hereditary cancer predisposition in a child with cancer. Pediatr Blood Cancer. 2019;66(11):e27916.

84. Prochniak CF, Martin LJ, Miller EM, Knapke SC. Barriers to and motivations for physician referral of patients to cancer genetics clinics. J Genet Couns. 2012;21(2):305-325. 
85. Cooksey JA, Forte G, Benkendorf J, Blitzer MG. The state of the medical geneticist workforce: findings of the 2003 survey of American Board of Medical Genetics certified geneticists. Genet Med. 2005;7(6):439-443.

86. Hoskovec JM, Bennett RL, Carey ME, et al. Projecting the Supply and Demand for Certified Genetic Counselors: a Workforce Study. J Genet Couns. 2018;27(1):16-20.

87. Hudson P, Zajo K, Gerhardt CA, Stanek J, Varga E. Defining the role of a genetic counselor within pediatric hematology and oncology comprehensive care teams: Perspectives of the provider team and patients. J Genet Couns. 2019;28(6):1139-1147.

88. Tsang S, Royse CF, Terkawi AS. Guidelines for developing, translating, and validating a questionnaire in perioperative and pain medicine. Saudi J Anaesth. 2017;11(Suppl 1):S80S89.

89. Centers for Disease Control and Prevention. The public health system and the 10 essential public health services. U.S. Department of Health and Human Services. https://www.cdc.gov/publichealthgateway/publichealthservices/essentialhealthservices.ht ml. Updated 06-26-2018. Accessed 03-23-2020.

90. Tak CR, Biltaji E, Kohlmann W, et al. Cost-effectiveness of early cancer surveillance for patients with Li-Fraumeni syndrome. Pediatr Blood Cancer. 2019;66(5):e27629.

91. Accreditation Council for Genetic Counseling. Practice-based competencies for genetic counselors. 2019. 